\title{
EISCAT and Cluster observations in the vicinity of the dynamical polar cap boundary
}

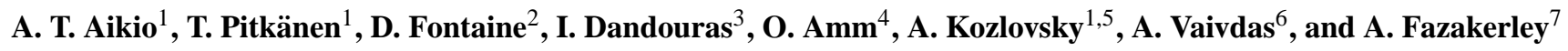 \\ ${ }^{1}$ Department of Physical Sciences, University of Oulu, P.O. Box 3000, 90014, Finland \\ ${ }^{2}$ CETP/UVSQ, Velizy, France \\ ${ }^{3} \mathrm{CESR} / \mathrm{CNRS}$, Toulouse, France \\ ${ }^{4}$ Finnish meteorological Institute, Helsinki, Finland \\ ${ }^{5}$ Sodankylä Geophysical Observatory, Sodankylä, Finland \\ ${ }^{6}$ Swedish Institute of Space Physics, Angströmlaboratoriet, Uppsala, Sweden \\ ${ }^{7}$ Mullard Space Science Laboratory, University College, London, UK
}

Received: 16 March 2007 - Revised: 14 December 2007 - Accepted: 20 December 2007 - Published: 4 February 2008

\begin{abstract}
The dynamics of the polar cap boundary and auroral oval in the nightside ionosphere are studied during late expansion and recovery of a substorm from the region between Troms $\emptyset\left(66.6^{\circ}\right.$ cgmLat) and Longyearbyen $\left(75.2^{\circ}\right.$ cgmLat) on 27 February 2004 by using the coordinated EISCAT incoherent scatter radar, MIRACLE magnetometer and Cluster satellite measurements. During the late substorm expansion/early recovery phase, the polar cap boundary (PCB) made zig-zag-type motion with amplitude of $2.5^{\circ}$ cgmLat and period of about $30 \mathrm{~min}$ near magnetic midnight. We suggest that the poleward motions of the PCB were produced

energized by waves, which at Cluster altitudes were observed as BBELF (broad band extra low frequency) fluctuations.

The four-satellite configuration of Cluster revealed a sudden poleward expansion of the PSBL by $2^{\circ}$ during $\sim 5 \mathrm{~min}$. The beginning of the poleward motion of the PCB was associated with an intensification of the downward FAC at the boundary. We suggest that the downward FAC sheet at the PCB is the high-altitude counterpart of the Earthward flowing FAC produced in the vicinity of the magnetotail neutral line by the Hall effect (Sonnerup, 1979) during a short-lived reconnection pulse.
\end{abstract} by bursts of enhanced reconnection at the near-Earth neutral line (NENL). The subsequent equatorward motions of the PCB would then represent the recovery of the merging line towards the equilibrium state (Cowley and Lockwood, 1992). The observed bursts of enhanced westward electrojet just equatorward of the polar cap boundary during poleward expansions were produced plausibly by particles accelerated in the vicinity of the neutral line and thus lend evidence to the Cowley-Lockwood paradigm.

During the substorm recovery phase, the footpoints of the Cluster satellites at a geocentric distance of $4.4 R_{E}$ mapped in the vicinity of EISCAT measurements. Cluster data indicate that outflow of $\mathrm{H}^{+}$and $\mathrm{O}^{+}$ions took place within the plasma sheet boundary layer (PSBL) as noted in some earlier studies as well. We show that in this case the PSBL corresponded to a region of enhanced electron temperature in the ionospheric $\mathrm{F}$ region. It is suggested that the ion outflow originates from the $\mathrm{F}$ region as a result of increased ambipolar diffusion. At higher altitudes, the ions could be further

Correspondence to: A. T. Aikio

(anita.aikio@oulu.fi)
Keywords. Ionosphere (Auroral ionosphere; Electric fields and currents; Storms and substorms)

\section{Introduction}

\subsection{Polar cap boundary and reconnection}

The reconnection between the terrestrial magnetic field lines and the IMF field lines was first discussed by Dungey (1961). During southward IMF, merging of closed geomagnetic field lines with the IMF may take place on the dayside magnetopause at low latitudes. The subsequent tailward transport of open field lines, reconnection at the tail neutral line and sunward convection of closed field lines produce a two-cell convection pattern in the ionosphere. In a steady state picture all the open flux created by dayside reconnection is closed by reconnection at the nightside distant neutral line (DNL) and at any moment the reconnection rates are equal. However, it has been suggested already by Russell (1972) that the dayside and nightside reconnection are separate processes, which may have different rates. Especially during substorms,

Published by Copernicus Publications on behalf of the European Geosciences Union. 
sudden reconnection is expected to take place at the nearEarth neutral line (NENL). This reconnection starts to affect the amount of open flux only when the last closed field line is reconnected.

Siscoe and Huang (1985) modelled unbalanced dayside reconnection by assuming that magnetic flux from the closed field line region enters the polar cap through a restricted part of the circular open-closed boundary (OCB) on the dayside (obviously mapping to the neutral line along the dayside magnetopause) and they termed this curved line segment the "merging line" or "merging gap". When the dayside merging rate was assumed to exceed that of the nightside merging, the polar cap at all local times was increasing in radius. Plasma flow accross the polar cap boundary occured only at the merging gaps, whereas at other local times the OCB moved with the plasma flow. Thus, the OCB outside merging lines was termed "adiaroic".

Lockwood et al. (1990) and Cowley and Lockwood (1992) discussed the polar cap motion and excitation of flows as a result of solar wind-magnetosphere coupling. They considered the case when merging on the dayside (flux transfer events, FTE) or/and in the nightside (substorm) is a localized and impulsive process. In dayside (nightside) reconnection, the addition (decrease) of flux on the dayside (nightside) creates a two-cell flow pattern, which tends to move the OCB equatorward (poleward) of the previous location. The foci of the convection vortices are displaced from the dawn-to-dusk meridian towards day (night) in the case of dayside (nightside) reconnection.

During northward IMF, merging may happen poleward of the cusps. For pure northward orientation, this merging of open geomagnetic field lines with the IMF generates lobecell convection in the magnetosphere and in the ionosphere (Reiff and Burch, 1985). However, when the IMF $B_{y}$ component is non-zero, closed field lines also reconnect with the IMF on the equatorward side of the cusp and generate merging-cell convection (Nishida et al., 1998; Tanaka, 1999). Open field lines generated by the reconnection on closed field lines convect tailward and subsequently reconnect in the twisted neutral sheet producing asymmetric merging cells in the ionosphere as shown, for example, by Grocott et al. (2005).

The ionospheric projection of the OCB is the polar cap boundary (PCB). The polar cap boundary determination can be done by using particle boundaries (Newell et al., 1996a,b), optical images (Baker et al., 2000; Brittnacher et al., 1999; Hubert et al., 2006), incoherent scatter (IS) radars (de la Beaujardiere et al., 1991; Blanchard et al., 1995, 1996; Moen et al., 2004; Ostgaard et al., 2005; Aikio et al., 2006) and coherent radars (Chisham et al., 2004; Wild et al., 2004). These methods are discussed in detail in the paper by Aikio et al. (2006) as well as the new IS-radar method that will be utilized in this study. Since it is not based on satellite overpasses, the temporal evolution of the PCB location can be followed. The advantage of this method is good spatial and temporal resolution.

1.2 Phenomena occurring in the vicinity of the nightside polar cap boundary

The nightside oval has been studied by satellite passes for several decades. Nowadays the plasma environment in the night side oval is typically divided into two main populations, the central plasma sheet (CPS) and the plasma sheet boundary layer (PSBL). There is no one commonly accepted way to identify these regions. An early definition comes from Eastman et al. (1984): "The plasma sheet boundary layer is a temporally variable transition region located between the magnetotail lobes and the central plasma sheet". Even though much of the oval dynamics is attributed to the PSBL, Newell et al. (1996a,b) note that discrete arcs may lie within the CPS and that CPS is not independent of substorm cycle.

The plasma sheet boundary layer is often occupied by filamentary (Alfvénic) FACs, intense fluxes of upward and downward electron beams and intense low-energy ion outflows (e.g. Keiling et al., 2001; Tung et al., 2001). Velocity dispersed ions of type-2, VDIS-2, are typically observed there and they are considered as a signature of quasi-steady reconnection (Sotirelis et al., 1999). The VDIS-2 ion spectra show sharp low energy cutoffs, which are smoothly dispersed in latitude (high energies occurring poleward of low energies).

Ion outflow from the ionosphere to the magnetosphere is a complicated phenomenon, which may be produced by a number of mechanisms. Ion outflows as a function of location, season, solar and magnetic activity have been studied in several papers (see e.g. Yau and Andre, 1997, and Wilson et al., 2001, 2004, and references therein). Substorm effects on ion outflows have been studied by Wilson et al. (2004), who find that regardless of substorm size, the nightside auroral zone outflow rate increases by about a factor of 2 after onset, reaching its peak level after about $20 \mathrm{~min}$. The PSBL, especially during substorms, is an important source of upflowing ions in the nightside (Tung et al., 2001; Ober et al., 2001).

Magnetic reconnection merging open field lines in the magnetotail affects first plasma within the PSBL. The effect of the Hall term in magnetic reconnection was first proposed by Sonnerup (1979), who predicted that the Hall term produces an additional four current loops in the vicinity of the reconnection site. The FACs of this current system are such that in the outermost region near the plasma sheet/tail lobe boundary, field-aligned currents flow out of the magnetic reconnection site. In the adjacent region, just inside the outflowing current layer, field-aligned currents flow into the magnetic reconnection site. Hence, the FACs of the Hall current circuit form a thin double-sheet structure near the separatrix layer. Hall-MHD simulations showed that such smallscale currents can be seen even away from the reconnection site (Yamade et al., 2000). 
Geotail observations in the vicinity of the magnetic reconnection site of the near-Earth magnetotail during substorm onsets by Nagai et al. (2001, 2003) and Ueno et al. (2002, 2003) have confirmed the existence of the Hall current system near the PSBL/lobe boundary. Nagai et al. (2001) demonstrated that the counterstreaming electrons in the outermost layer are common characteristics of magnetic reconnection at substorm onsets, and they identified outflowing currents with $6-13 \mathrm{nA} \mathrm{m}^{-2}$ in the outermost layer of the plasma sheet/tail lobe boundary in the immediate vicinity of the magnetic reconnection site. Nagai et al. (1998) suggested that the outflowing current is carried by the measured medium energy (near $3 \mathrm{keV}$ ) electrons, which stream into the magnetic reconnection site. Recent Cluster observations of the magnetic effect of the Hall currents and the $500-2000 \mathrm{eV}$ electrons flowing towards the reconnection site in the tail at a distance of about $-18 R_{E}$ have given more support to the Hall-current concept (Asano et al., 2006).

Some evidence that the FACs associated with the Hall currents in the vicinity of the reconnection site would continue to the ionosphere was provided by observations of Ober et al. (2001). They studied an event, where the Polar s/c crossed the PCB near the end of the expansion phase and close to magnetic midnight and found that the boundary was associated with severe east-west plasma flow shears and multiple FACs. At the boundary, Alfvén waves carried a FAC pair with upward FAC on the equatorward and downward FAC on the poleward side. Yamade et al. (2000) estimated from their simulation that the current densities at the ionospheric level would be $5 \mu \mathrm{A} / \mathrm{m}^{2}$.

The aim of the paper is to study the dynamics of the polar cap boundary and the oval during one substorm event giving insight into reconnection processes. The polar cap boundary and the poleward part of the oval is studied by using EISCAT VHF radar measurements while MIRACLE magnetometers give information of the distribution of electrojets within the oval. Sections 3 and 4 concentrate on ground-based observations of substorm expansion and early recovery. Cluster pass provides valuable data of plasma environment at an altitude of about $21000 \mathrm{~km}$ above the auroral ionosphere during late recovery phase of the substorm. These satellite-ground coordinated measurements are discussed in Sect. 5. Finally, conclusions are given in Sect. 6.

\section{Measurements and data analysis}

The EISCAT radar experiments used in this paper had the following characteristics. The EISCAT VHF radar, located in Troms $\varnothing$ (TRO, geographic: $69.59^{\circ} \mathrm{N}, 19.22^{\circ} \mathrm{E}, \mathrm{cgm}: 66.58^{\circ}$, $102.94^{\circ}$ ), was pointed at $30^{\circ}$ elevation with azimuth of $0.5^{\circ}$ to the west from geographic north. The EISCAT Svalbard Radar (ESR) $42 \mathrm{~m}$ antenna in Longyearbyen (LYR, geographic: $78.15^{\circ} \mathrm{N}, 16.03^{\circ} \mathrm{E}$, cgm: $75.22^{\circ}, 111.94^{\circ}$ ) is fixed to point in the field-aligned direction and the ESR $32 \mathrm{~m}$ an-

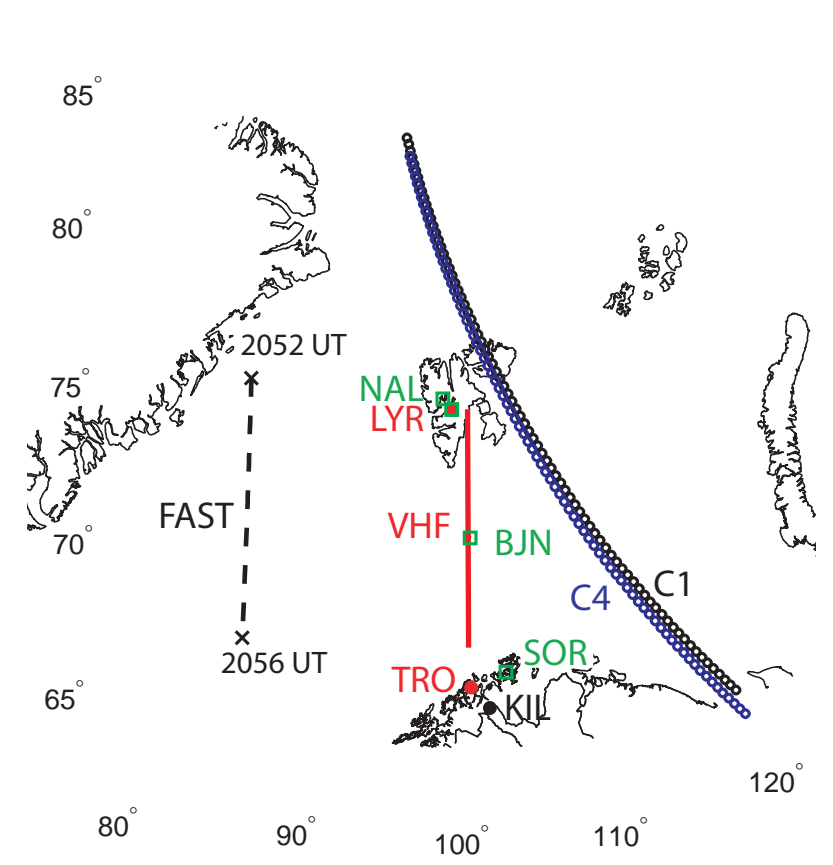

Fig. 1. Cluster orbit for satellites $\mathrm{C} 1$ and $\mathrm{C} 4$ mapped to the altitude of $100 \mathrm{~km}$ by using the T89c model with $K_{p}=3$. The coordinate system is cgm. The footpoints of $\mathrm{C} 2$ and $\mathrm{C} 3$ are located between those of $\mathrm{C} 1$ and $\mathrm{C} 4$. The projection of the EISCAT VHF beam and the mapped FAST orbit are also shown. The sites of the VHF radar (TRO), the ESR radar (LYR) and Kilpisjärvi all-sky camera (KIL) are indicated by dots. Squares show the northernmost stations of the MIRACLE magnetometer chain.

tenna was directed at $30^{\circ}$ elevation to azimuth of $0.5^{\circ}$ to the west from geographic north. In this paper, we will not utilize the $32 \mathrm{~m}$ data. The VHF and ESR $42 \mathrm{~m}$ beam locations are shown in Fig. 1.

In this study, we estimate the location of the polar cap boundary (PCB) by the EISCAT radar measurements using a method, which is described in detail by Aikio et al. (2006). Electron precipitation in the nightside ionosphere increases the electron temperature $T_{e}$ due to the collisional heating of background plasma by the primary and secondary electrons. Since the energy flux of precipitating electrons in the oval is typically higher than that in the polar cap (polar rain precipitation), electron temperature changes can be used to track the polar cap boundary. When a radar is measuring at a low elevation angle in the north-south direction, the $T_{e}$ profile along the beam depends both on the horizontal variations in the temperature as well as the height profile of the temperature with each measurement point representing different altitude-latitude pair. Typically, $T_{e}$ increases with altitude. When the PCB is situated between Troms $\varnothing$ and Longyearbyen, the ESR $42 \mathrm{~m}$ antenna, measuring in the field-aligned direction, provides the height profile of $T_{e}$ in the polar cap. We subtract from the VHF $T_{e}$ profile the polar cap $T_{e}$ profile 


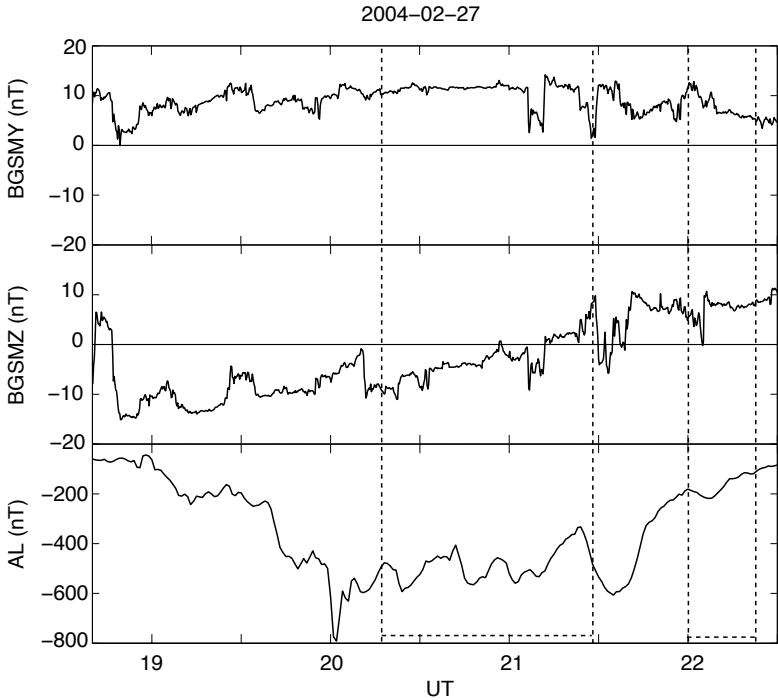

Fig. 2. Two top panels show IMF $B_{y}$ and $B_{z}$ in the GSM coordinates as measured by the ACE satellite. The time is delayed by $55 \mathrm{~min}$ to account for propagation to the subsolar magnetopause. Bottom panel shows the AL index. The two time intervals marked by vertical lines relate to the PCB fluctuations as observed by EISCAT, and the Cluster pass in the PSBL in the end of the recovery phase, respectively.

at corresponding altitudes to get a $\Delta T_{e}$ profile. Then, a positive value of $\Delta T_{e}$ indicates that electron temperature at that latitude (and altitude) is enhanced as compared to a corresponding altitude in the polar cap. By searching the polewardmost latitude where the temperature difference is positive, we get a proxy for the PCB location.

In this paper, we have used two criteria for the PCB search. Method 1 puts the boundary in the polewardmost location where the electron temperature difference plus error stays above zero (as in Aikio et al., 2006) and Method 2 in the location, where the actual electron temperature difference curve crosses zero. If the $T_{e}$ errors are small and the electron temperature gradient sharp at the boundary, these curves are close to each other.

The temporal resolution of the PCB location is defined by the resolution used in the low-elevation radar data analysis. In this event, a 2-min resolution is used until 21:30 UT, 4min resolution during 21:30-22:00 UT and 5-min resolution 22:00-22:40 UT. The integration time of data was increased as the received signal power decreased to keep the errors at an acceptable level. The range integration in the data analysis resulted in a latitude resolution ranging from $0.18^{\circ}$ to $0.36^{\circ}$ cgmLat, higher resolutions corresponding to lower latitudes.

The equivalent east-west currents in the ionosphere were calculated from the magnetic X components of a north-south chain of MIRACLE magnetometer stations by using 1-Dupward field continuation method (Vanhamäki et al., 2003).
The northernmost of the stations (NAL, LYR, BJN and SOR) used are shown in Fig. 1.

The Cluster orbit during the studied event is explained in Sect. 5.1. We have utilised measurements from four Cluster instruments: the Electric Field and Wave Instrument, EFW (Gustafsson et al., 1997), the Fluxgate Magnetometer, FGM (Balogh et al., 1997), the Plasma Electron And Current Experiment, PEACE (Johnstone et al., 1997) and the Cluster Ion Spectrometry, CIS (Réme et al., 2001).

The EFW experiment consists of two pairs of spherical probes deployed in the spin plane to measure the electric field. The component of the electric field along the spin axis is not measured. To study the electric field fluctuations, we use high time resolution, $40 \mathrm{~ms}$. These data are presented in the DSI (despuned inverse) coordinate system, which is very close to GSE. In DSI the $\mathrm{x}$-axis is in satellite spin plane as close as possible to the $\mathrm{x}$-axis in GSE, the $\mathrm{z}$-axis is along the satellite spin axis with the inversed sign of spin vector because then it is as close as possible to there z-axis in GSE, and $y$-axis closes the right-handed coordinate system.

Data from the FGM instrument is used to calculate the field-aligned current densities for each s/c separately. The contribution of the Earth's average geomagnetic field is subtracted from the spin-resolution (4s) measurement and the remaining variations are fitted to the magnetic field of an infinite current sheets.

The HEEA (High-Energy Electron Analyser) sensor of the PEACE instrument is used. It covers the energy range from $36.2 \mathrm{eV}$ to $23.7 \mathrm{keV}$. The full $4 \pi$ solid angle coverage is composed of a grid of 12 polar bins by 32 azimuthal bins; each bin is $15^{\circ}$ by $11.25^{\circ}$. The data are acquired simultaneously in all 12 polar bins while the azimuthal data are gathered as the satellite spins.

The CIS experiment consists of two distinct instruments measuring complete 3-D ion distributions: the CIS-1/CODIF spectrometer which separates the major ion species $\left(\mathrm{H}^{+}\right.$, $\mathrm{He}^{++}, \mathrm{He}^{+}$, and $\mathrm{O}^{+}$), with energies up to $40 \mathrm{keV} / \mathrm{e}$ and the CIS-2/HIA analyser which gives the ion distributions (without mass resolution) from $5 \mathrm{eV} / \mathrm{e}$ to $32 \mathrm{keV} / \mathrm{e}$.

\section{IMF and mainland optical observations}

The IMF was measured by the ACE satellite at $X_{\mathrm{GSM}} \sim 218 R_{E}$. During the studied time interval, the solar wind speed stayed rather steady, at about $410 \mathrm{~km} / \mathrm{s}$, which resulted in a time delay of about $55 \mathrm{~min}$ to the dayside subsolar magnetopause at about $10 R_{E}$. In the following discussion, we use these delayed times. The dynamic pressure of the solar wind remained small $(2-3.5 \mathrm{nPa})$ throughout the time interval. After being several hours in the northward direction, the IMF $B_{z}$ decreased abruptly from $5 \mathrm{nT}$ to $-15 \mathrm{nT}$ at about 18:45 UT (Fig. 2). For the next two hours, the IMF $B_{z}$ varied between -15 and $-5 \mathrm{nT}$ and $B_{y}$ was about $10 \mathrm{nT}$. The IMF turned northward at 21:10 UT, 
but was again negative for a short time interval during 21:30-21:40 UT, after which the IMF remained northward (value about $10 \mathrm{nT}$ ) until the end of the studied time interval, 22:40 UT with an exception of a short-lived decrease of $B_{z}$ to zero at 22:08 UT.

The optical observations were made on the mainland by the Kilpisjärvi (KIL, geographic: $69.02^{\circ} \mathrm{N} 20.79^{\circ} \mathrm{E}$; cgm: $65.76^{\circ} 104.49^{\circ}$ ) all-sky camera (see Fig. 1). The camera showed a very faint auroral arc drifting southward at 19:00 UT, which is a typical feature during a growth phase of a substorm (data not shown). In spite of an onset of $\mathrm{Pi} 2$ pulsations at about 19:20 UT at mid-latitude magnetometers (NUR, UPS, HAD), the activated arcs continued to drift equatorward. At 19:41 UT a westward travelling surge (WTS) appeared from the east and produced poleward expansion of auroras in the studied MLT zone. So, obviously the substorm onset time was within the 19:20-19:40 UT time interval and the onset location was to the east of KIL. The AL index in Fig. 2 shows also a rapid decrease starting at about 19:40 UT.

The WTS stayed in the field-of-view (f-o-v) of the KIL all-sky camera (ASC) until 20:08 UT. After that, the WTS moved towards west and the auroral bulge was left behind. The bulge expanded poleward and disappeared beyond the KIL ASC f-o-v $\left(70^{\circ}\right.$ cgmLat in the northern direction) at 20:08 UT. The AL index shows a sharp minimum at 20:02 UT (Fig. 2), but the equivalent currents of the westward electrojet (WEJ) integrated along the whole north-south chain of the MIRACLE magnetometers reach their maximum only at 20:20 UT (curve not shown, but look at Fig. 5). Traditionally, the time of the AL minimum (WEJ maximum) would mark the end of the expansion phase and beginning of the recovery phase (e.g. McPherron, 1995). However, the magnitude of the AL index stays high until 21:40 UT and a rapid recovery starts only after that.

In this paper, we concentrate on the time interval after 20:00 UT, which covers the late expansion and recovery phases of the substorm. From this time period we have no optical observations from the region of interest.

\section{EISCAT radar and ground magnetic observations}

\subsection{PCB and F-region electron and ion temperatures}

Figure 3 shows the $T_{e}$ of the VHF radar in the time-latitude coordinate system and the black curve is the PCB determined by using this data together with the ESR field-aligned $T_{e}$ data (Method 1). The figure shows that the electron temperature is increased at all latitudes equatorward of the PCB down to $69.6^{\circ}$, which is the lowest latitude provided by the method (corresponding to a height of $200 \mathrm{~km}$ ).

Ion temperatures shown in Fig. 4 behave differently. They are increased within a relatively narrow zone in the vicinity of the PCB, and only during a part of the observing time.
Lockwood and Fuller-Rowell (1987a, b) and Lockwood et al. (1988) introduced the idea that a band of high $T_{i}$ might form on the equatorward (poleward) side of a contracting (expanding) polar cap near dawn and dusk so that the enhanced $T_{i}$ would always be located on the trailing side of the boundary. The explanation required two things. First, initially an equilibrium state had been reached where the thermospheric winds and ion flows had adapted to each other. Then, a sharp boundary of ion flows would move rapidly in horizontal direction producing ion frictional heating at locations where ion flows had turned into opposite direction than the winds. Experimental evidence of this effect were provided by Lockwood et al. (1988) showing observations of the motion of a sharp flow reversal boundary in the dawn sector and by Davies et al. (2002) using data from the pre-noon sector. However, Moen et al. (2004) noted that the trailing edge concept of enhanced $T_{i}$ by Lockwood et al. was not consistent with their observations made near noon. They observed a band of high $T_{i}$ which persisted for $8 \mathrm{~h}$ and zig-zagged northsouth. This band of high $T_{i}$ could locate on the equatorward side of the flow reversal boundary as it was moving equatorward, on both sides of the flow reversal boundary, and at times it was not related to the flow reversal boundary at all. In addition, the band of high dayside $T_{i}$ was located on open field lines, but its equatorward edge was not a good proxy for the OCB.

In this nightside event, the poleward edge of the high $T_{i}$ band follows quite well the PCB determined by the poleward edge of high $T_{e}$ until 21:14 UT. Data from the coherent HF radars of the Super Dual Auroral Radar Network (SuperDARN, Greenwald et al., 1995) (not shown) reveal that before 19:30 UT a two-cell convection pattern prevails, with the VHF radar measuring the south-westward plasma flow in the evening convection cell. There has been enough time for the neutral wind to adapt itself to the 2-cell pattern. The substorm onset is followed by the arrival of the WTS to the longitude of EISCAT during 19:41-20:08 UT. The auroral bulge behind the head of the WTS expands poleward, carrying along eastward plasma flows (westward current, see also Fig. 5). When these eastward plasma flows meet the assumed westward winds, increased ion frictional heating is expected on the equatorward side of the poleward expanding boundary according to the trailing edge concept. This is exactly what is seen during 20:10-20:26 UT (period A) and also 20:4220:58 UT (period C).

Since the PCB spends only a relatively short time interval at higher latitudes, the neutral winds are not expected to be affected much by the ion drag and the trailing edge concept may not work during an equatorward recovery of the PCB. Indeed, during 20:26-20:42 UT (period B), the band of increased $T_{i}$ is very wide and even though some part of it is on the poleward side of the $\mathrm{PCB}$, the main part of it is equatorward of the boundary. During 20:58-21:12 UT (period D), $T_{i}$ is clearly less enhanced and coincides with the PCB. After a temporal maximum at 21:12 UT, the $T_{i}$ enhancement 
Electron temperature 27 Feb 2004

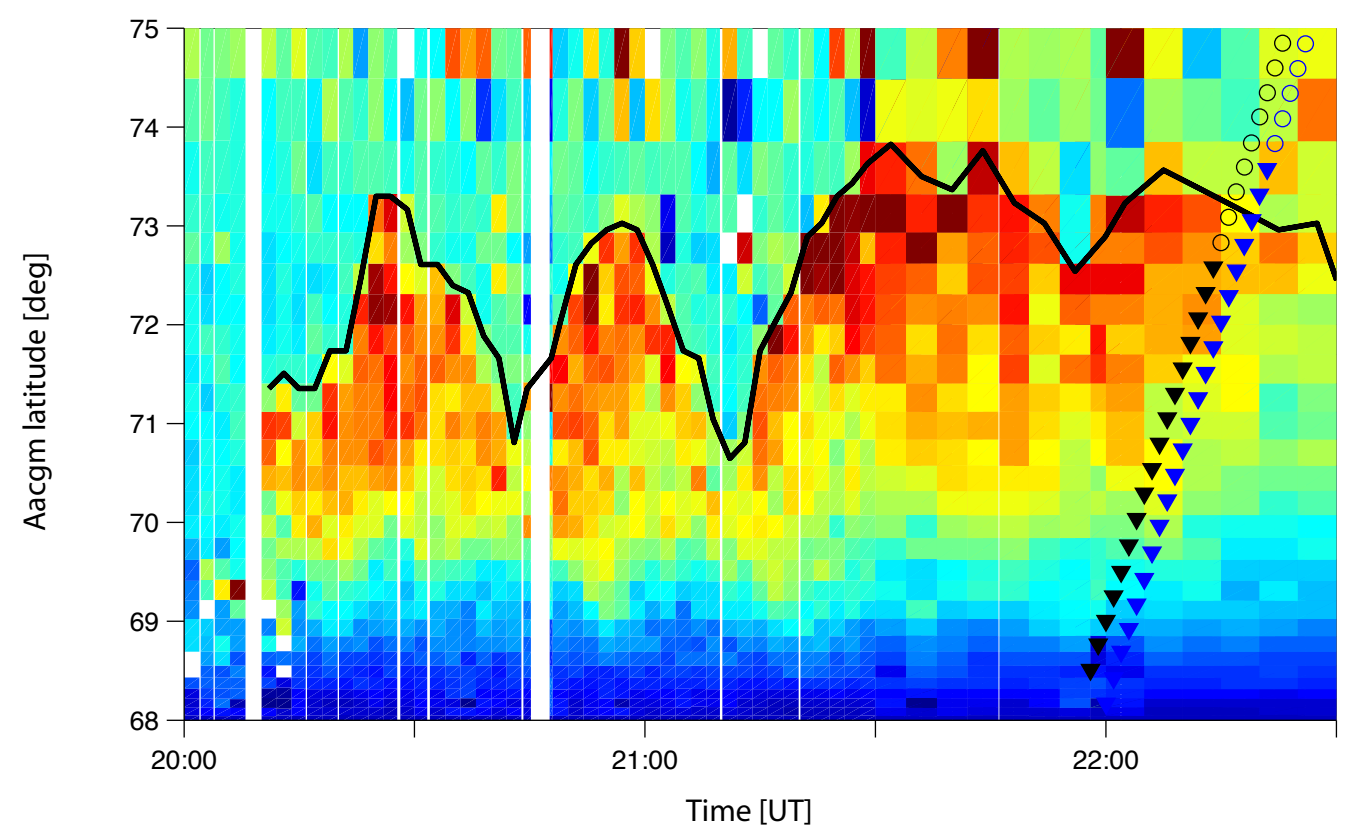

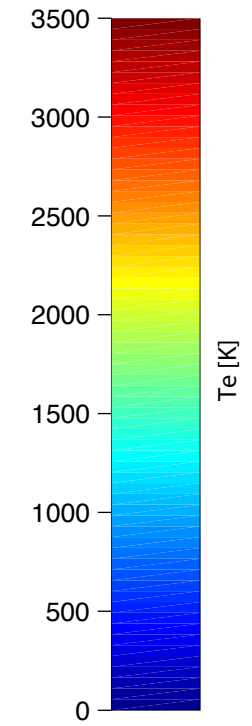

Fig. 3. Electron temperature measured by the VHF radar. The black curve is the PCB based on this data and the ESR field-aligned Te measurement. Cluster C1 (black) and C4 (blue) orbits are marked by triangles at locations of ion outflow.

Ion temperature 27 Feb 2004
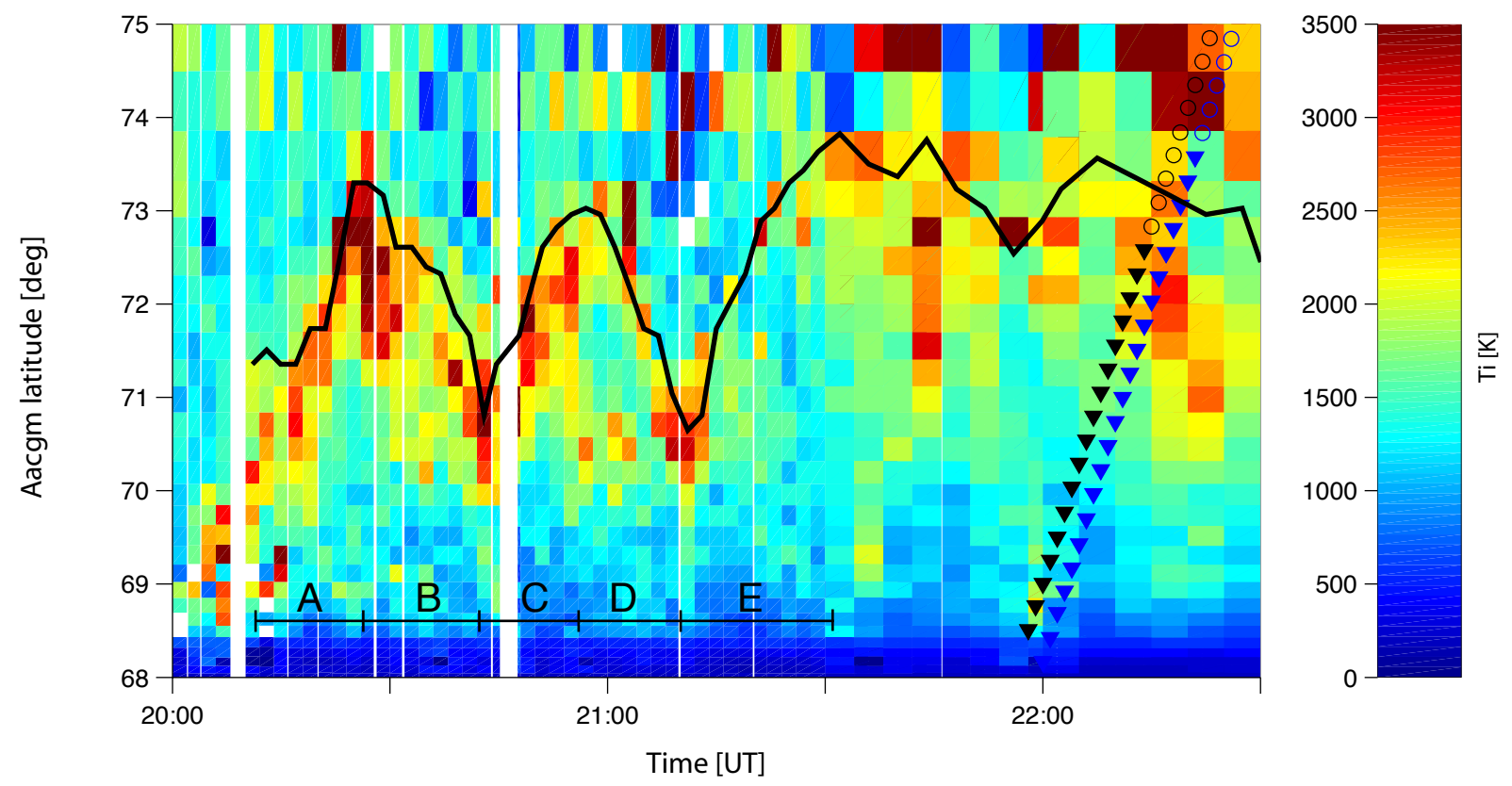

Fig. 4. Ion temperature measured by the VHF radar in the same format as Fig. 3. Time intervals denoted by A to E are shown in the lower part of the figure.

disappears entirely and is not visible during period $\mathrm{E}$ (the poleward motion of the PCB). Since the $T_{i}$ enhancement is proportional to $\left(\mathbf{v}_{\mathbf{i}}-\mathbf{v}_{\mathbf{n}}\right)^{2}$, obviously the velocity difference between ions and neutrals has become small.

\subsection{Equivalent currents and the PCB}

The equivalent east-west currents are shown in Fig. 5. After 19:30 UT, a westward current region drifting southward 




Fig. 5. Equivalent east-west current as deduced from the MIRACLE data. The thick (thin) black line indicates the polar cap boundary from the EISCAT VHF radar by using Method 1 (Method 2). The dotted lines are mapped Cluster s/c C1-C4 locations and the filled circles indicate positions where $\mathrm{C} 1$ and $\mathrm{C} 4$ observe ion outflow. The triangles with tip down are the locations of the s/c at 21:05 UT. The orbits of the satellites in latitude and longitude are shown in Fig. 1. The triangles with tip up are the locations of the PCB by each s/c (see text). The black square shows the PCB location from FAST data. Letters from A to E are same time intervals as in Fig. 4.

becomes visible. It is obviously associated with the activated aurora, also drifting equatorward. The steplike poleward expansion and intensification of the westward electrojet (WEJ) at 19:45 UT, is due to intrusion of the WTS to the magnetometer meridian from the east, as shown by the KIL all-sky camera. The poleward edge of the substorm current wedge (SCW) stays at about a constant latitude (about $70^{\circ} \mathrm{cgm}$ Lat) until 20:08 UT, after which a poleward expansion occurs. At the same time, a significant equatorward expansion of the SCW currents occurs, which results in a very wide oval, about $10^{\circ}$ in cgmLat.

The PCB can be estimated by the EISCAT radar method after 20:08 UT and then the PCB traces rather closely the poleward edge of the WEJ. An exception occurs in the very beginning (20:08-20:24 UT) of the time interval, when the intense WEJ seems to extend to the poleward side of the PCB. This may not be a real effect, but related to the sparsely located magnetometers within this region combined with bursts of intense currents.

The WEJ has three short-lived intensifications close to the PCB, which are associated with a simultaneous poleward expansion of the PCB. These start at 20:18 (period A), 20:49 (period C) and 21:15 UT (period E), i.e. they are separated by 25-30 min. These rather short-lived (duration about $10 \mathrm{~min}$ ) intesifications of the WEJ are restricted to latitudes poleward of approximately $70^{\circ}$ cgmLat.

Each expansion is followed by contraction, so that the result is a periodic oscillatory motion (zig-zag-type) of the PCB with an amplitude of about $2.5^{\circ}$. Alltogether 2.5 oscillations occur. When the last oscillation has reached its maximum at about 21:25 UT, the PCB doesn't return to a lower latitude, but stays in the north. At that time the IMF has become northward. 
During period C, the FAST satellite passes from north to south about $1.5 \mathrm{~h}$ earlier in MLT time (see Fig. 1). The FAST ions show the VDIS-2 signature and the polar rain electrons a velocity dependent cutoff (data not shown) indicating ongoing reconnection. For a polar cap boundary, we selected a location where high-energy (25 keV) ions appear and electron energy fluxes start to increase (20:54:00 UT). The mapped cgm latitude of the boundary is marked by a solid square in Fig. 5 and it is very close to the PCB location at the EISCAT longitude.

\subsection{Origin of PCB fluctuations}

During late substorm expansion, the polar cap boundary exhibits a zig-zag-type motion between about $70.5^{\circ}$ and $73^{\circ}$ cgmLat with a period of 25-30 min. The PCB motions can be explained by at least by three different mechanisms: (1) Large-scale spatial structures drifting in the east-west direction along the boundary, (2) Global oscillatory motions of the magnetosphere, and (3) Variations in flux reconnection rates. We will discuss these options below.

The poleward boundary of oval may sometimes host different wavelike structures or regions of enhanced luminosity, which can travel along the boundary (see e.g. Elphinstone et al., 1995). Since no global images of the auroral oval are available, we can't make the distinction (the KIL all-sky camera doesn't see far enough north). However, the oscillations observed are quite large in amplitude, $2.5^{\circ}$ in latitude and hence, if spatial features, they are very large in size.

Lyons et al. (2002) suggested that global mode Ps6 frequency oscillations could play a role in polar boundary intensification (PBI) events. Those events occur at the poleward boundary of the oval and the typical period is $10 \mathrm{~min}$, but sometimes 25-30 min periods are seen. Lyons et al. (2002) proposed that the PBI events would be manifestations of a global oscillatory mode of the magnetosphere. Those global ULF waves would modulate particle transport and magnetic fields in the whole nightside magnetosphere.

Global magnetospheric MHD cavity and/or waveguide modes are generally attributed to frequencies higher than $1 \mathrm{mHz}$ (periods shorter than $15 \mathrm{~min}$ ). For excitation of cavity modes, a pressure pulse or a sudden change in IMF could act as a trigger. Indeed, Ostgaard et al. (2005) found oscillations of the nightside PCB at periods of 10-15 min.

Also sub-mHz oscillations have been found from the magnetosphere, especially at $0.5 \mathrm{mHz}$ (30 min period) (Kepko et al., 2002; Kepko and Spence, 2003). It has been suggested that at sub- $\mathrm{mHz}$ frequencies, the magnetosphere could be a passive oscillator, driven by external periodic forcing by the solar wind.

In this event, the period of the PCB oscillations is 25$30 \mathrm{~min}$. However, none of the magnetometer data we have checked (the MIRACLE magnetometers, the INTERMAGNET mid/low latitude magnetometers, and the GOES 10 and 12 magnetometers at the geostationary orbit on the dayside) show any evidence of global ULF waves. Therefore we rule out this mechanism.

The third mechanism is provided by variations in the reconnection rates between the terrestrial magnetic field lines and the IMF field lines. This issue is discussed in Introduction. The balance between the dayside and nightside reconnection determines the location of the PCB. If a nightside reconnection pulse (relatively short-lived period of increased reconnection rate) takes place, the localized region of increased closed flux is pushing the PCB poleward within that region. After the pulse has decayed, the polar cap boundary is relaxing to equilibrium position at all local times.

In this event, we observe three clear poleward expansions and two first of them are also associated with recoveries. In addition, Fig. 5 shows that poleward expansions during periods $\mathrm{A}, \mathrm{C}$ and $\mathrm{E}$ are associated with an enhanced WEJ in the vicinity of the boundary. We suggest that the cause is enhanced precipitation, which obviously originates from fieldlines Earthward, but rather close to the neutral line. These enhancements remain local and don't extend to the main oval, so obviously there is no large-scale effect on the magnetotail. We also checked geostationary particle data from the LANL satellites (data not shown) and noted that these periods are not associated with particle injections to the geostationary orbit unlike the substorm onset before 20:00 UT.

Since the EISCAT experiment mode used in this measurement didn't allow determination of the 2-D plasma velocity and boundary orientation, we were not able to calculate the ionospheric reconnection rates. However, since the poleward expansions of the PCB are associated with enhanced electrojets and hence plausibly of particle precipitation in the vicinity of the boundary, and since FAST data suggest that the boundary motion occurs at least within a region 1.5 MLT wide, we favour option 3 (reconnection pulses) as the explanation of these fluctuations.

There are some observations of the typical time scales associated with PCB motions. On the dayside, Lockwood et al. (2005) reported motions of the entire dayside PCB both poleward and equatorward during different substorm phases. Those motions occurred on time scale of hour(s). In addition to that pulsing on time scales of 2-20 min during southward IMF was observed. As mentioned earlier in this section, Ostgaard et al. (2005) found oscillations of the nightside PCB at periods of $10-15 \mathrm{~min}$. In the very beginning of substorm expansion, poleward expansion has been observed to occur in the form of individual bursts, which are separated by 210 min (Aikio et al., 2006). One could also note that bursty bulk flow (BBF) events in the central plasma sheet organize themselves in 10-min time scale flow enhancements (Nakamura et al., 2005). It is believed that fast flows are due to acceleration in the reconnection region. The $30 \mathrm{~min}$ period observed in this study is longer than the time scales quoted above, but with the same order of magnitude. 


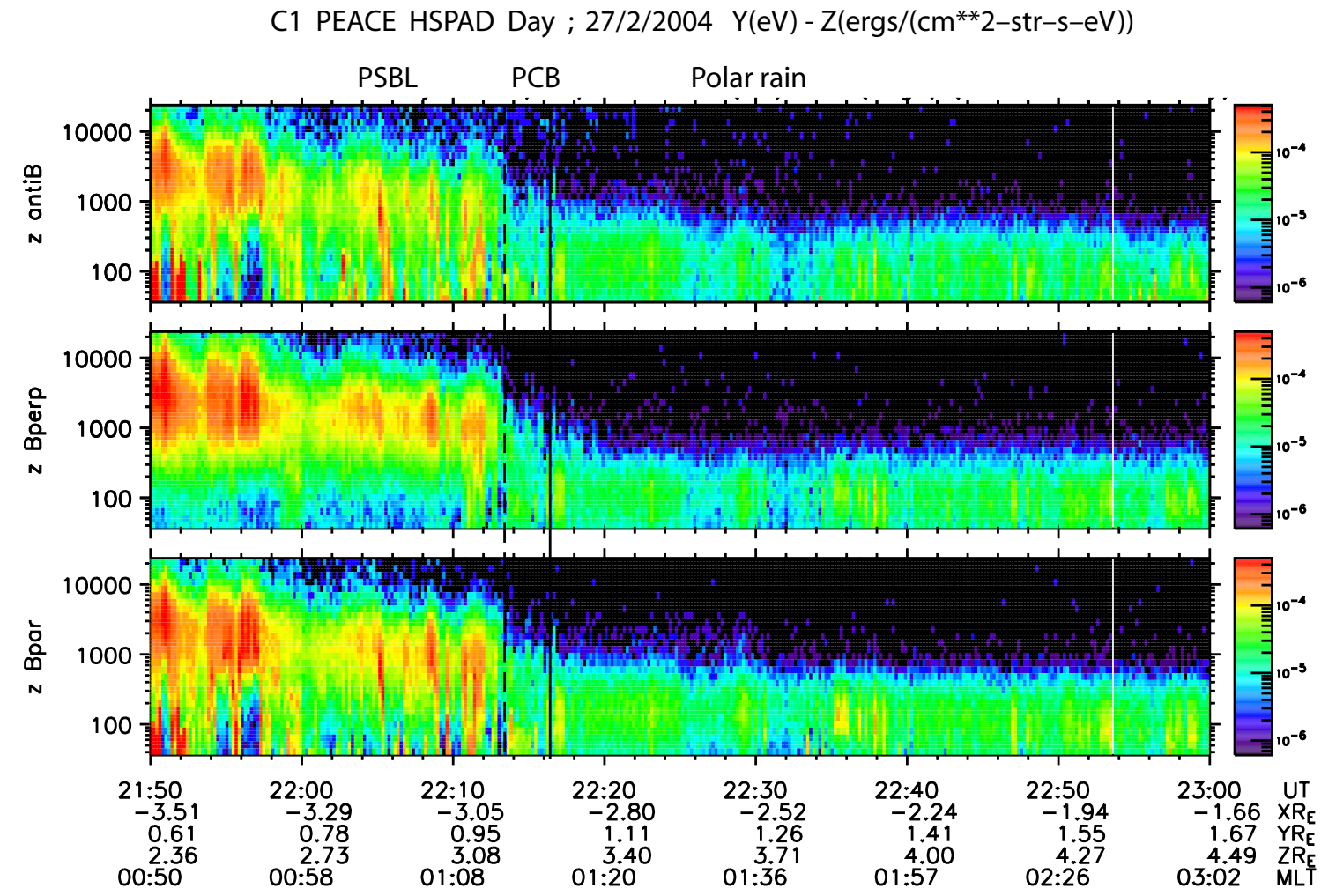

Fig. 6. PEACE measurement on $\mathrm{C} 1$ of electron energy fluxes in units of erg $\mathrm{cm}^{-2} \mathrm{sr}^{-1} \mathrm{~s}^{-1} \mathrm{eV}^{-1}$ in the upward (top), perpendicular (middle) and downward (bottom) directions. The PSBL and Polar rain regions are shown.

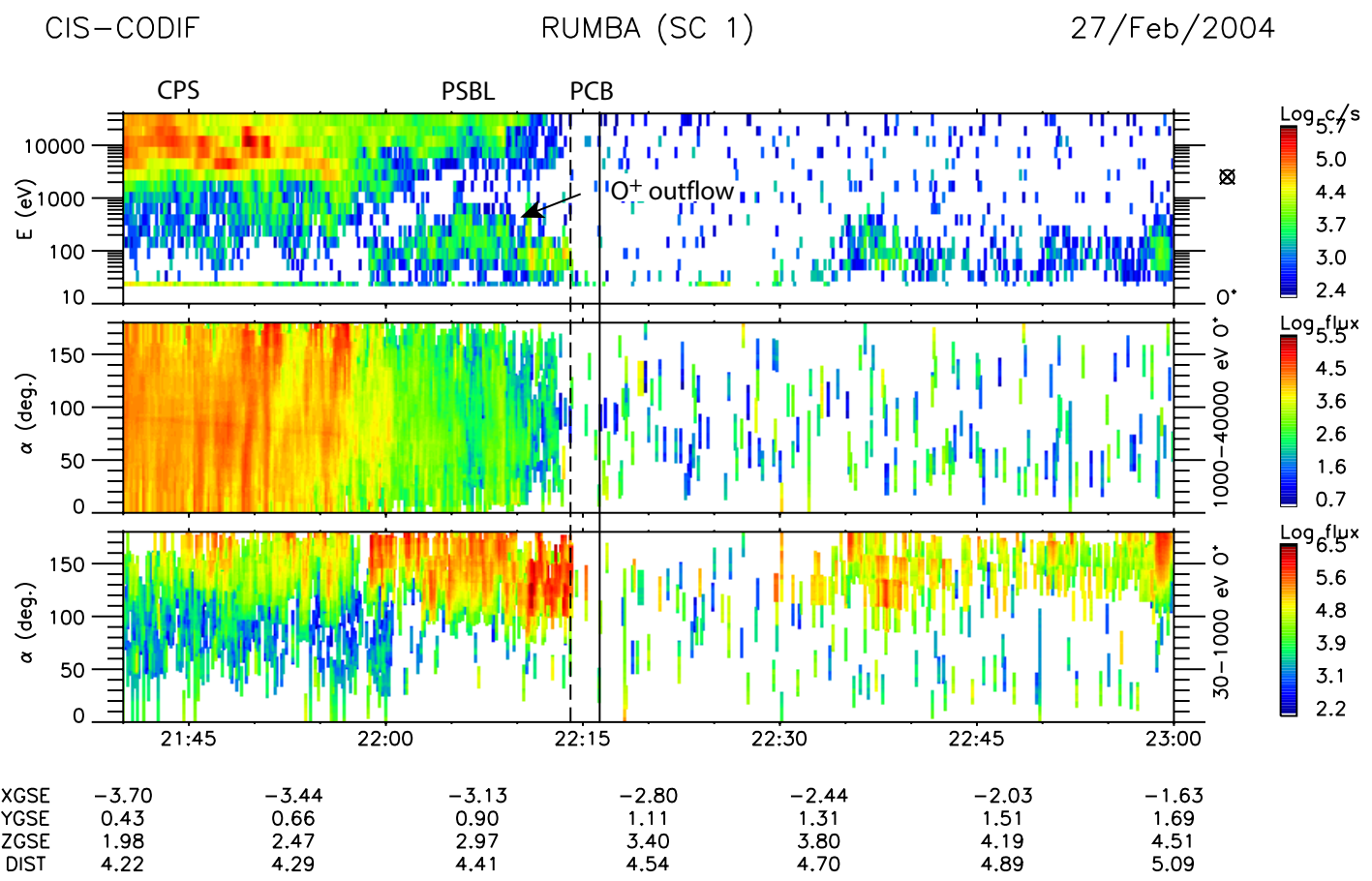

Fig. 7. Omnidirectional CIS CODIF spectrograms for $\mathrm{O}^{+}$ions in corrected-for-detection-efficiency counts per sec (top), pitch angle distribution for the upper energy population $\left(1-40 \mathrm{keV}\right.$ ), in particle flux units (ions $\mathrm{cm}^{-2} \mathrm{~s}^{-1} \mathrm{sr}^{-1} \mathrm{keV}^{-1}$ ) (middle) and pitch angle distribution for the lower energy population $(30 \mathrm{eV}-1 \mathrm{keV})$ (bottom). 


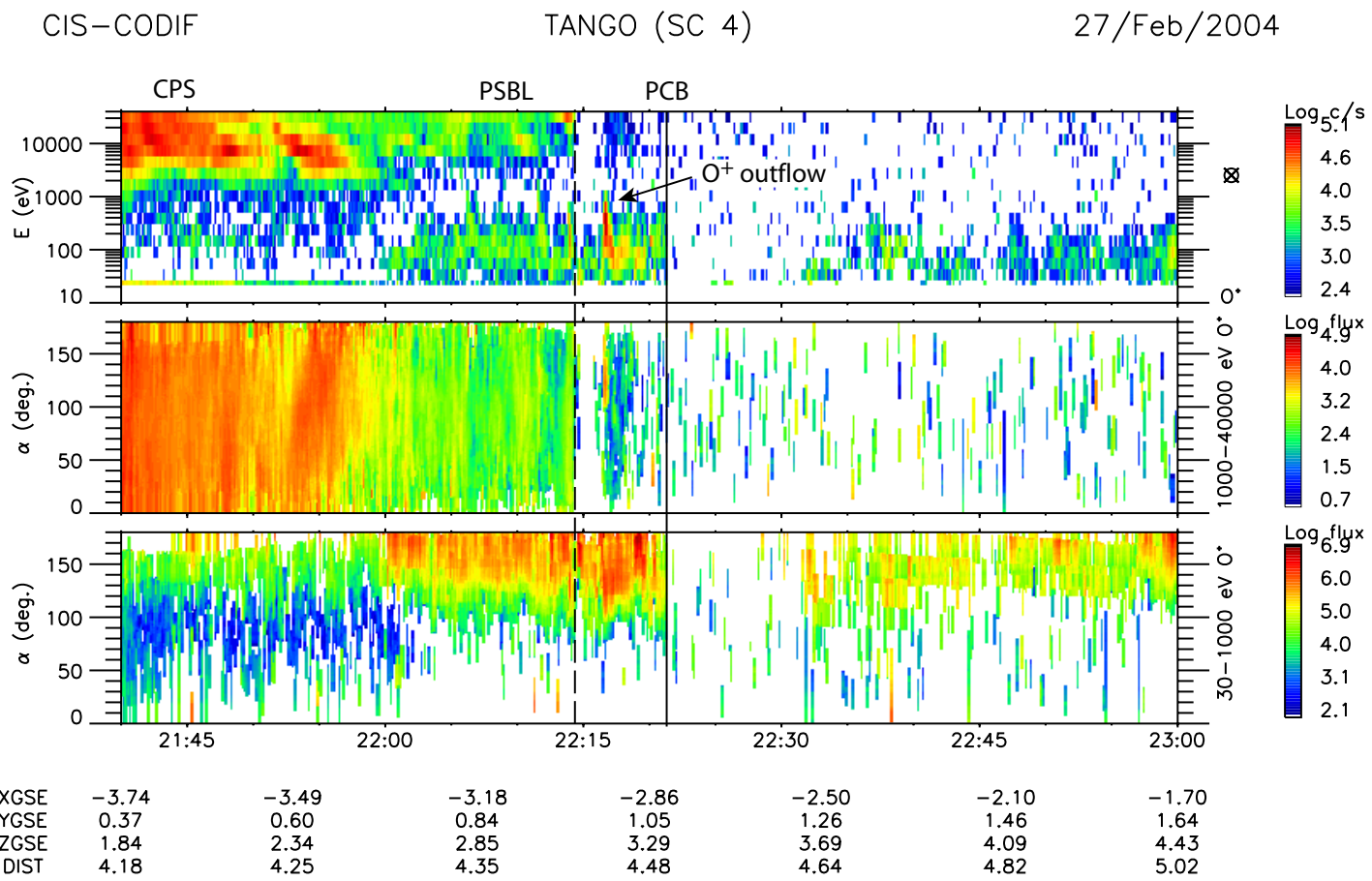

Fig. 8. Same as Fig. 7, but for s/c C4.

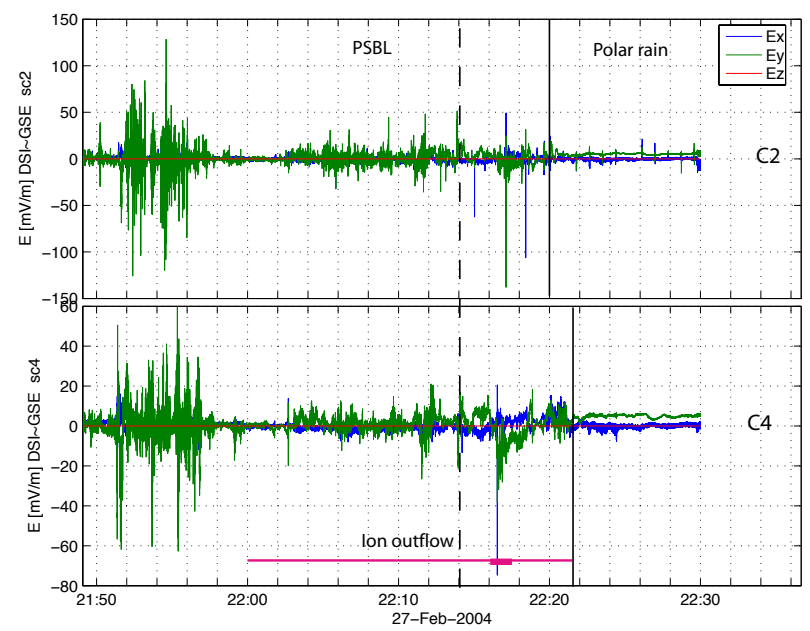

Fig. 9. Electric field components from the EFW instrument in the DSI coordinate system for C2 (top) and C4 (bottom). The PSBL and Polar rain regions are marked by vertical lines. For s/c C4, the time interval of ion outflow is indicated by the horizontal line and the time of maximum flux intensity by a thicker line.

\section{Cluster observations during substorm recovery}

\subsection{Magnetospheric regions traversed and ion outflow}

The four Cluster satellites were on the perigee pass over the Northern Hemisphere during the substorm recovery phase. The Cluster orbit mapped along magnetic field lines to a
$100 \mathrm{~km}$ altitude by the T89c model is shown in Fig. 1 . The orbits are located to the east of the VHF beam, $10^{\circ}$ cgmLon at 22:14 UT. The four satellites form a closely spaced stringof-pearls in the order $\mathrm{C} 4, \mathrm{C} 2, \mathrm{C} 3$ and $\mathrm{C} 1$ from west to east. The orbits in the time-latitude coordinate system are shown in Fig. 5, where it can be seen that $\mathrm{C} 1$ leads the northward motion, then come $\mathrm{C} 3, \mathrm{C} 2$ and $\mathrm{C} 4$.

Figure 6 is selected to show the electron populations encountered by the $\mathrm{C} 1$ satellite. The change from the CPS to the PSBL plasma takes place around 21:50 UT, where the high-energy (up to several tens of $\mathrm{keV}$ ) particle populations start to decrease in energy. In addition, downgoing and upgoing electrons with energies down to the lower limit of the instrument, typical of the PSBL, appear. The PSBL terminates at the polar cap boundary and is followed by polar rain electrons with energies of a few hundred $\mathrm{eV}$.

Figures 7 and 8 show the oxygen populations for $\mathrm{C} 1$ and C4 (no CIS data was available from C2 and C3). Hydrogen ions show very similar behaviour (data not shown). The CPS is dominated by isotropic several tens of $\mathrm{keV}$ ions. In the PSBL, the low-energy edge of the energy spectrum for the high energy population increases with latitude, which is a characteristic signature of velocity-dispersed ions of type 2 . The VDIS- 2 signature is interpreted to be produced by reconnection in the magnetotail: the highest energy ions arrive poleward of the lower energy ions, which spend a longer time when traveling from the reconnection site to the ionosphere and thus suffer from a greater inward drift. 


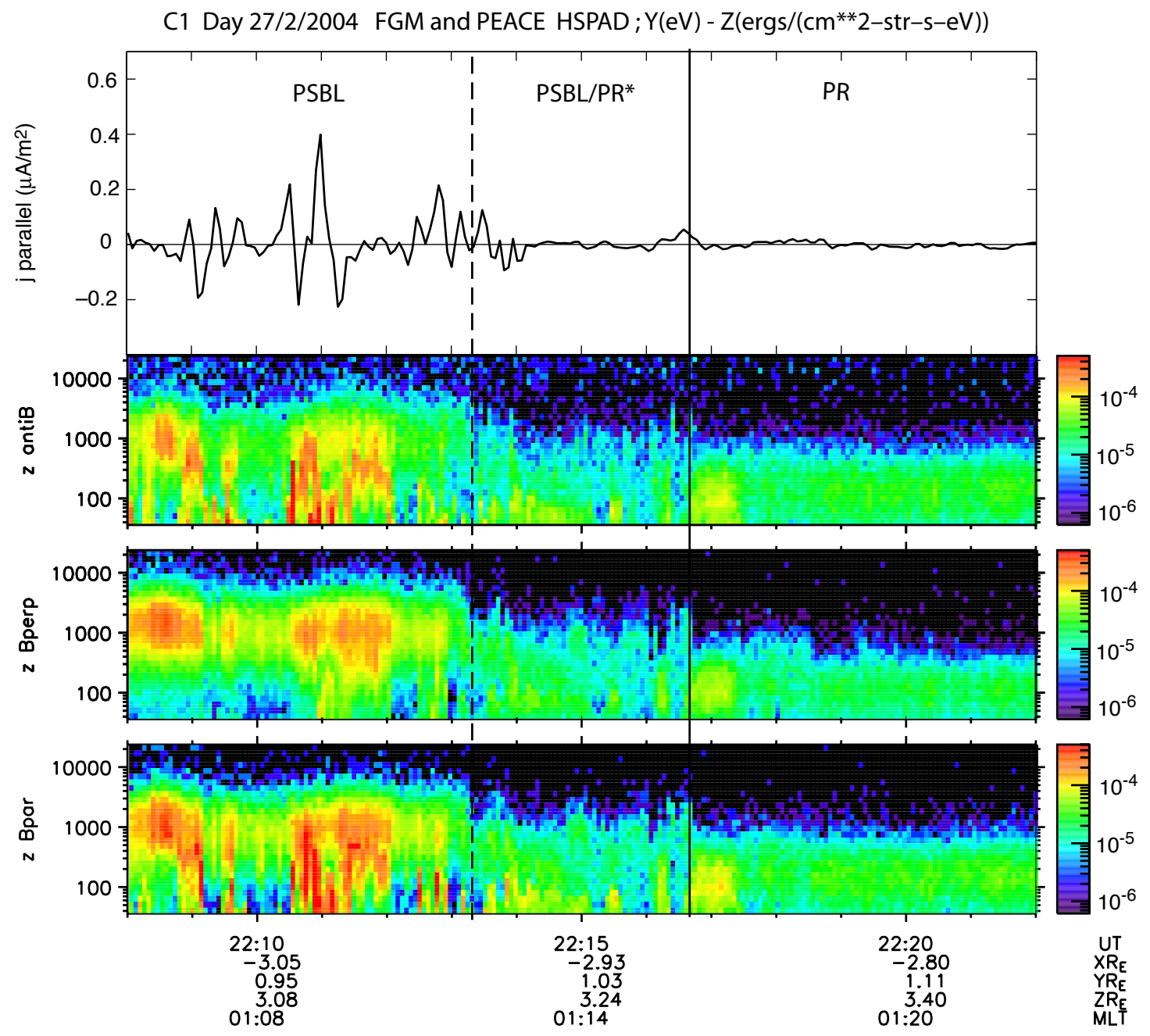

Fig. 10. Downward FAC for $\mathrm{C} 1$ (top panel) and PEACE data in the same format as Fig. 6 (bottom panels).

Both satellites show upflowing (see the bottom panel for pitch-angle of low-energy ions) $\mathrm{O}^{+}$and $\mathrm{H}^{+}$ions within the PSBL region with energies of $50-500 \mathrm{eV}$. Hydrogen fluxes exceed $10^{7} \mathrm{~cm}^{-2} \mathrm{~s}^{-1}$ while oxygen fluxes are somewhat smaller. This region of ion outflow is marked by filled dots in Fig. 5. One can see that this $4^{\circ}$ cgmLat ( $6^{\circ}$ cgmLat) wide region by $\mathrm{C} 1$ (C4) corresponds to the poleward part of the oval and the poleward part of the westward electrojet region up to the PCB. In Figs. 3 and 4 the ion outflow region is shown by triangles. Ion outflow coincides with a region of enhanced electron temperature rather than increased ion temperature in the ionospheric F region. Elevated electron temperature increases the scale height of ions and the ambipolar diffusion coefficient. For example, the measured ion temperature of $2500 \mathrm{~K}$ (at an altitude $400 \mathrm{~km}$ ) corresponds to a thermal energy of $0.3 \mathrm{eV}$ for ions. If the observed ions are of ionospheric origin, they must be energized between the ionosphere and the Cluster altitude $\left(3.4 R_{E}\right)$. One possibility is energization by waves.
Figure 9 shows the full resolution $(40 \mathrm{~ms}$, corresponding frequencies up to $12.5 \mathrm{~Hz}$ ) electric fields measured by satellites $\mathrm{C} 2$ and $\mathrm{C} 4$ (no data was available from $\mathrm{C} 1$ and $\mathrm{C} 3$ ). Two bursts of intense fluctuations can be seen. The most intense flux of upflowing ions measured by $\mathrm{C} 4$ occurs at about 22:17 UT and at the same time enhancement in the amplitude of electric field fluctuations are seen. These fluctuations belong to the family of broad band electrostatic extra low frequency (BBELF) waves which extend from DC to several hundred Hz. At least some of the wave modes classified as BBELF can heat the ions (André et al., 1998; Lynch et al., 2002). The heated ions are then pushed upward along magnetic field lines by the mirror force. The region of BBELF waves may extend well below the Cluster altitudes. 
C3 Day 27/2/2004 FGM and PEACE HSPAD; Y(eV) - Z(ergs/(cm**2-str-s-eV))

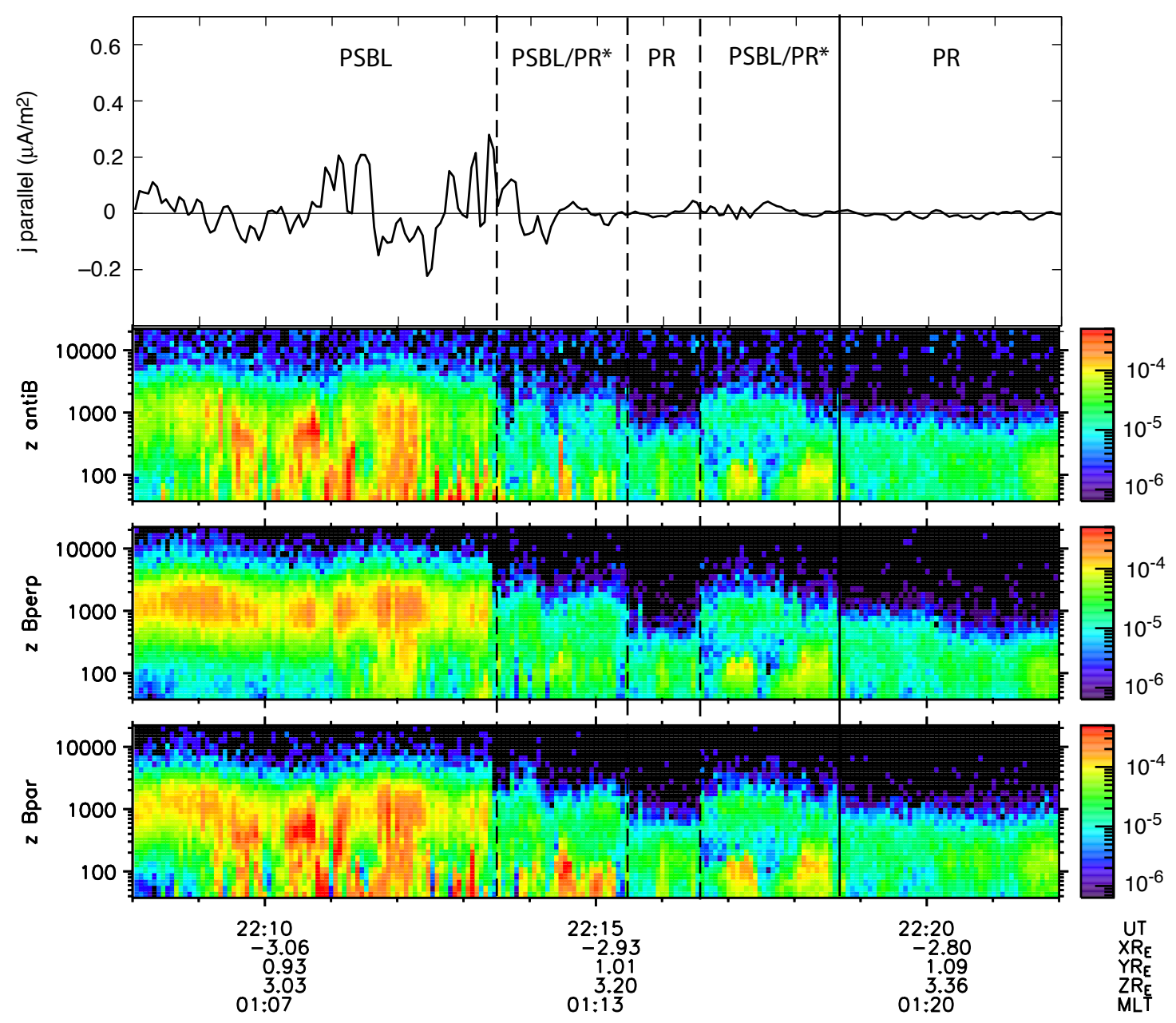

Fig. 11. Downward FAC for C3 (top panel) and PEACE data in the same format as Fig. 6 (bottom panels).

5.2 Cluster measurements of electrons and field-aligned currents

Comparison of the PEACE electron data and the calculated FACs for all four Cluster satellites from the poleward part of the PSBL and beginning of the polar rain region are shown in Figs. 10-13. We first turn attention to the electron data to determine the location of the PCB.

At the polar cap boundary, the energetic electron fluxes drop off and polar rain begins. However, even in a stationary situation the boundary may be somewhat ambiguous, since field lines are convecting earthward after reconnecting at the neutral line and only electrons with infinite speed would trace the neutral line to the ionosphere. Determining which electrons are polar rain electrons on open field lines is also ambiguous because the energy of polar rain electrons varies from event to event. In this case, it seems that polar rain electrons occur at energies below $1 \mathrm{keV}$ (see also Fig. 6) and we use this definition to characterize polar rain (PR) electrons in Figs. 10-13. The location where the PR electrons are encountered is marked by a solid line. However, intense fluxes of a few $\mathrm{keV}$ electrons drop off at a lower latitude and define another boundary for $\mathrm{C} 1$, which is marked by a dashed line (Fig. 10). Equatorward of this boundary, the electron population is characteristic of the PSBL. Between these two boundaries, electron fluxes at $\mathrm{C} 1$ are structured and weak, but extend somewhat above the $1-\mathrm{keV}$ limit. We have marked this region by PSBL/PR ${ }^{\star}$, since it has characteristics of both regions.

The satellite to follow $\mathrm{C} 1$ on the poleward orbit is $\mathrm{C} 3$. The unstructured polar rain is observed continuously on the poleward side of the last solid line and the PSBL is located equatorward of the first dashed line in Fig. 11. Inside the $\mathrm{PSBL} / \mathrm{PR}^{\star}$ region, fluxes have increased from that of $\mathrm{C} 1$ and in the middle of this region there is a short interval when electrons are typical of polar rain. 


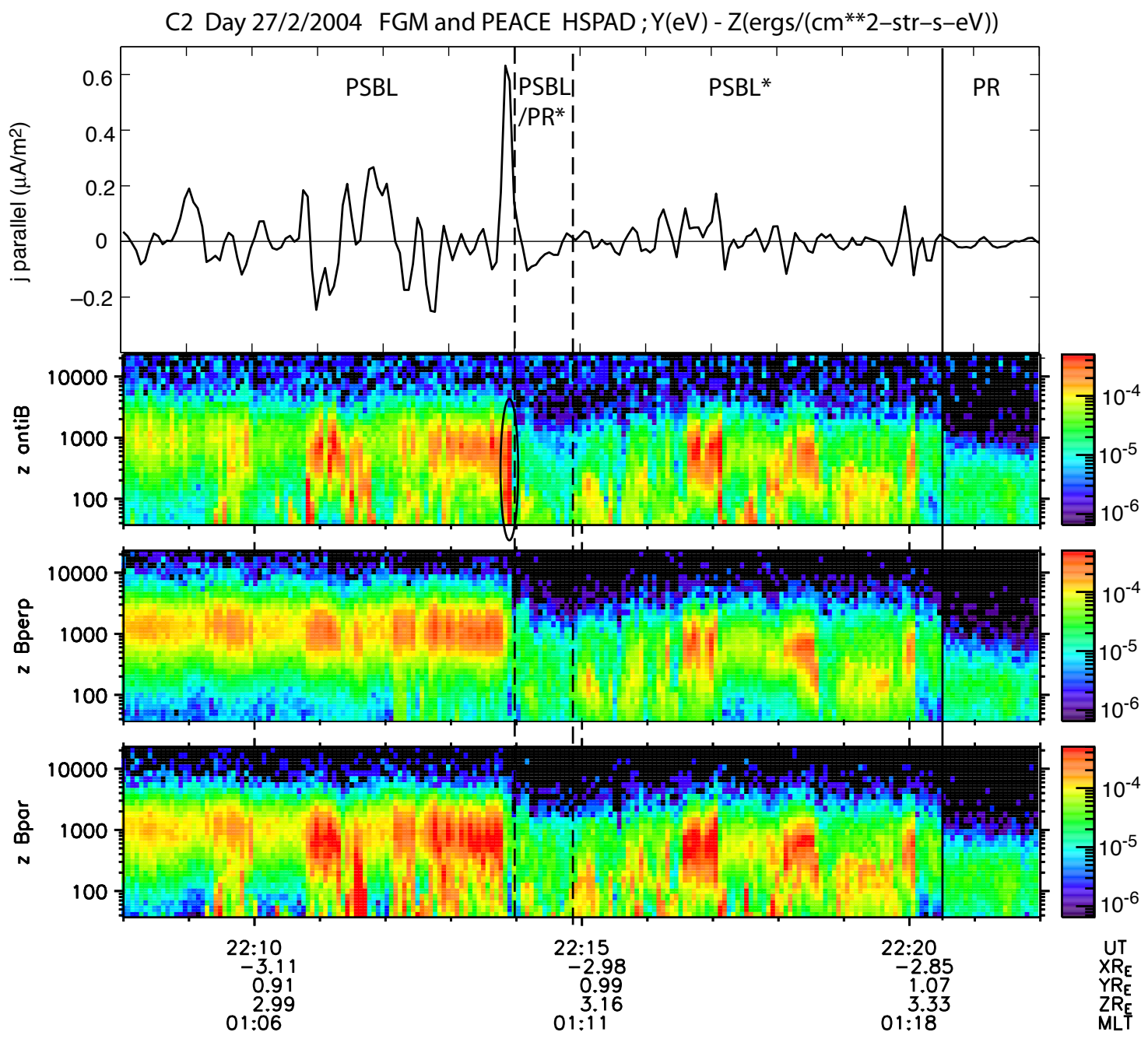

Fig. 12. Downward FAC for $C 2$ (top panel) and PEACE data in the same format as Fig. 6 (bottom panels).

C2 follows C3 and and for a short period of time C2 is embedded in a region of low-energy weak fluxes, marked as $\mathrm{PSBL} / \mathrm{PR}^{\star}$ in Fig. 12. After that, a pronounced enhancement of electron fluxes is observed by $\mathrm{C} 2$. For $\mathrm{C} 4$ the increase of fluxes is observed almost immediately poleward of the dashed line (Fig. 13).

We argue that the PSBL has suddenly expanded poleward and this expanded region we denote by $\mathrm{PSBL}^{\star}$.

The top panels of Figs. 10 to 13 show the FACs. The fieldaligned current densities have been calculated by assuming that they are stationary sheet currents aligned perpendicular to $\mathrm{s} / \mathrm{c}$ orbit (sheet alignment in the east-west direction). The values shown are at the satellite altitude and to get the values in the ionosphere they must be multiplied by about 100 due to the decrease of the flux tube cross-sectional area towards the ionosphere.

Alternating upward and downward currents are seen in the PSBL by all four s/c. When averaged over the PSBL, a net downward FAC is obtained, which is in accordance with the Region 1 current direction in the post-midnight sector. Earlier observations of magnetospheric FACs in the PSBL have also been in accordance with the Region 1 current directions (e.g. Ohtani et al., 1988).

Satellites C1 and C3 measure a similar broad (width about $0.4^{\circ}$ in latitude) fluctuating FAC region with preference of downward FAC and intensity up to $0.2 \mu \mathrm{A} / \mathrm{m}^{2}$ in the vicinity of the poleward edge of the PSBL. Satellites C2 and C4 cross this boundary 30-60 s later and they observe that the downward FAC structure just at the boundary has intensified and become narrower. The FAC density is $0.6 \mu \mathrm{A} / \mathrm{m}^{2}$ at $\mathrm{C} 2$ and $0.4 \mu \mathrm{A} / \mathrm{m}^{2}$ at $\mathrm{C} 4$. For all $\mathrm{s} / \mathrm{c}$, the downward $\mathrm{FAC}$ region extends on both sides of the boundary and upward FAC regions of clearly smaller intensities are observed on both sides of the downward FAC.

The current carriers of the intense downward FAC are upgoing electrons of broad energy range up to $2 \mathrm{keV}$ at $\mathrm{C} 2$ 


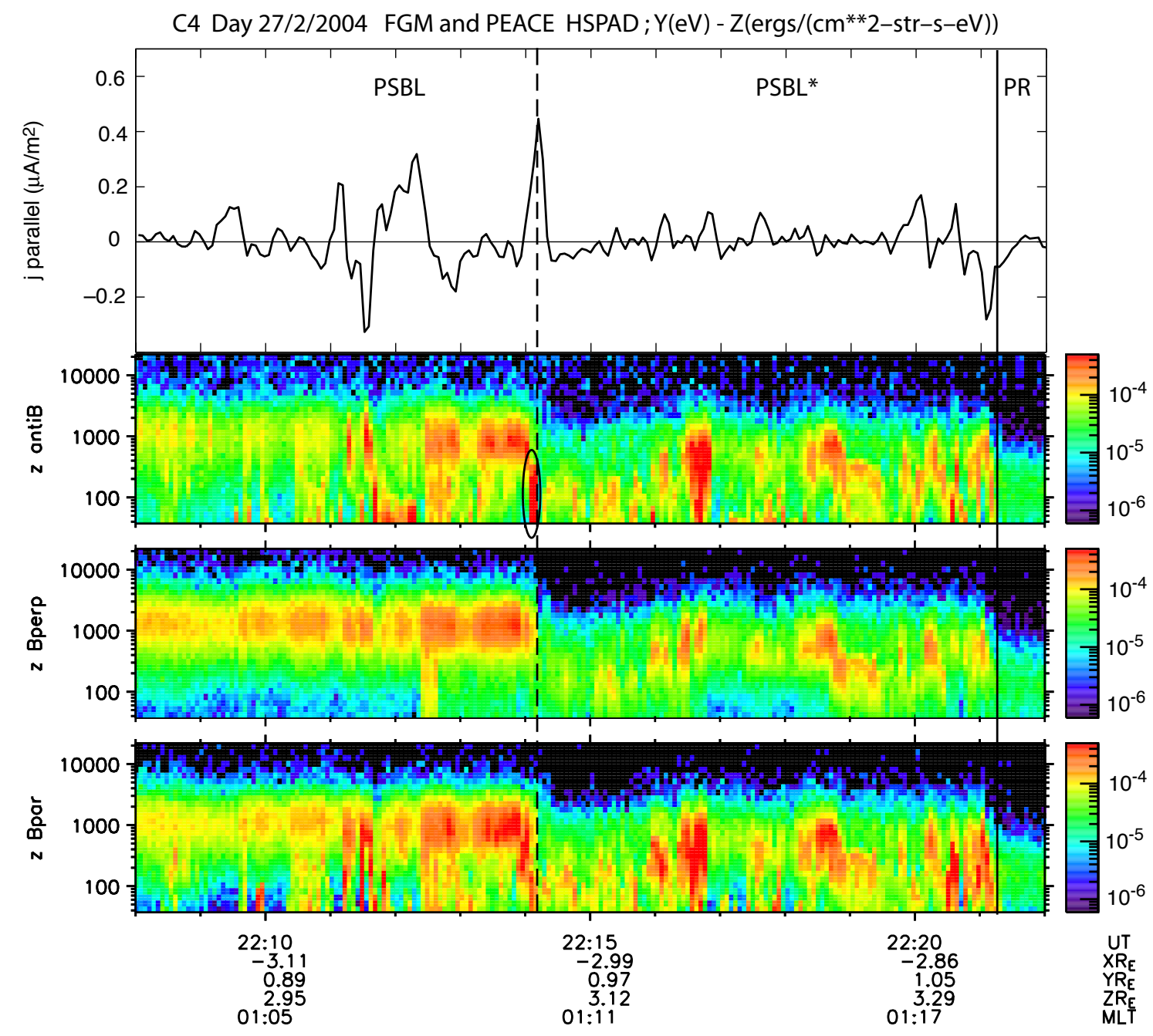

Fig. 13. Downward FAC for C4 (top panel) and PEACE data in the same format as Fig. 6 (bottom panels).

(22:13:52 UT) and up to $400 \mathrm{eV}$ at C4 (22:14:12 UT), as seen in the second panel of Figs. 12 and 13 (feature is encircled). As discussed by Aikio et al. (2004), these are probably electrons of ionospheric origin, which have been accelerated below the satellite. There seems to be a positive correlation between the FAC density and the maximum energy of the upflowing electrons.

\subsection{Interpretation of Cluster observations in terms of a tem- poral change}

We turn our attention again to Figs. 7 and 8 , where the time instants corresponding to the first vertical line (first exit from the PSBL) and the last vertical line (final exit to polar rain) from Figs. 10 and 13 are added. At C1, no ions are observed poleward of the PSBL. At C4, higher energy ions disappear at the time of the first exit from the PSBL and then after a few minutes fluxes recover at lower intensity. Hydrogen ions (data not shown) show a similar gap and the recovered fluxes are more intense than those of $\mathrm{O}^{+}$shown, but smaller than in the original PSBL. These $\mathrm{H}^{+}$fluxes also extend to the location of the final PCB.

The low-energy $\mathrm{O}^{+}$population at $\mathrm{C} 4$ which is flowing upward from the ionospheric direction, doesn't show a similar gap, but maximum fluxes and energies are encountered at the point where the high-energy ion population recovers. The poleward boundary of upflowing ions extend to the location of the new PCB.

To clarify the event in terms of spatial and temporal evolution, we show the downward FAC by all the four s/c as a function of time and corrected geomagnetic latitude in Fig. 14. The FAC intensity is color coded with yellow and red colors corresponding to downward FAC, blue color to upward FAC and green color to no FAC. (The interpolation used in plotting the $\mathrm{s} / \mathrm{c}$ data causes some artificial structuring in the currents so that typically the current sheets seem to contain 
four fluctuations). The data from satellites show a consistent picture: several FAC structures drifting southward are seen by all the satellites, e.g. around 22:06, 22:09, 22:11 and 22:13 UT. The FACs tend to occur in pairs with upward FACs equatorward of the downward FACs, which is a typical signature of morningside arcs (Aikio et al., 1993). The slope of the structures remains about the same and corresponds to drift speed of about $1 \mathrm{~km} / \mathrm{s}$ equatorward. So, the FAC structures are likely to be associated with auroras drifting equatorward in the poleward part of the auroral bulge. The drift speed is rather high, but the line-of-sight measurements from the Iceland East SuperDARN radar (data not shown) reveal similar plasma convection velocities during this time interval slightly north of Cluster footpoints.

The ionospheric current density at the original PCB can be get by multiplying the FAC density estimate based on an assumption of a stationary current sheet at Cluster altitude by a factor of $100 \cdot 0.3=30$, where 100 comes from the geometry of the flux tubes and 0.3 from the motion of the current sheet towards the poleward moving satellites. The equatorward velocity of the current sheet can be deduced from Fig. 14 and it is about $1000 \mathrm{~m} / \mathrm{s}$, whereas the mapped satellite velocity in the poleward direction is $460 \mathrm{~m} / \mathrm{s}$. By inserting them in equation $v_{\text {sat }} /\left(v_{\text {sat }}+v_{\text {fac }}\right)$ (e.g. Aikio et al., 2004), we get a correction factor 0.3 . Thus $0.2 \mu \mathrm{A} / \mathrm{m}^{2}$ and $0.6 \mu \mathrm{A} / \mathrm{m}^{2}$ at $\mathrm{C} 1$ and $\mathrm{C} 4$, respectively, correspond to 6 and $18 \mu \mathrm{A} / \mathrm{m}^{2}$ at the ionospheric level.

A clear change in the drift pattern of Fig. 14 occurs close to $22: 15 \mathrm{UT}$. The equatorward drift has stopped and rather poleward moving structures can be seen. The plus-marks denote the exit from the PSBL and it is denoted by "original PCB". The final crossing to the polar cap is marked by stars and it is denoted as "final PCB".

In Fig. 15 only the perpendicular electron fluxes are selected from each s/c and they are stacked so that the common horizontal axis is the geomagnetic latitude. The string-ofpearls configuration during the studied time interval was such that the satellites were at a given latitude with 1-min separation. The two red lines show how a simultaneous event at all satellites would look like in the figure. The white dashed line shows the location of the "original PCB", which is drifting equatorward with the plasma (slope is larger than that of the red line which also corresponds to poleward motion at the same velocity as the satellites). At about 22:15 UT a change from equatorward drifting structures to poleward moving structures takes place, in accordance with FAC drifts in Fig. 14. The three black lines show structures which are moving poleward with a velocity that is slightly faster than the mapped satellite velocity in the poleward direction (the slopes of black lines are somewhat smaller than that of the red line). The identified structures are first observed by $\mathrm{C} 4$, then $\mathrm{C} 2$ and they seem to extend even to $\mathrm{C} 3$ producing there weak fluxes of electrons above $1 \mathrm{keV}$. Enhancement of low-energy fluxes at $\mathrm{C} 1$ occurs also in connection with this poleward expansion. The poleward expansion stops at about



Fig. 14. Downward FAC in time-latitude coordinates. The FAC magnitude is color coded and data from all four satellites is used.

22:19-22:20 UT and the final PCB latitude (solid white line) becomes as $73.6^{\circ}$.

To summarise the observations we note the following. All the poleward moving Cluster satellites cross a spatial boundary between 22:13-22:14 UT. After the crossing, polar rain type electrons are observed by all the other satellites but the last (C4). The most poleward satellite, $\mathrm{C} 1$, continues to see electrons of polar rain energies after that and ions disappear. For other satellites, the electron fluxes recover again and after a pause, high-energy ions reappear at $\mathrm{C} 4$. The drift patterns identified from FACs and electron structures indicate that around 22:15 UT a poleward expansion of the PSBL plasma occurs. The velocity of the poleward expanding boundary is only a little faster than the satellite velocity in the poleward direction, so that the boundary catches $\mathrm{C} 2$ and to some extent $\mathrm{C} 3$, but not properly $\mathrm{C} 1$. The duration of the poleward expansion is order of $5 \mathrm{~min}$. We suggest that we have observed a short-lived and possibly spatially localized reconnection burst at the nightside neutral line during substorm recovery.

The interesting observation is the downward FAC at the original PCB, just when it was about to start expanding poleward. The theoretical model of the Hall current system in the vicinity of the neutral line predicts field-aligned current out of the reconnection site. To our knowledge, there has not been conclusive evidence that this field-aligned current component would continue to the ionosphere. However, the data by Ober et al. (2001) and the data presented above, suggest this might be the case. Simultaneous and conjugate observations in the ionosphere and in the mid-tail would be needed to conclusively confirm this hypothesis. In this study, we find that the downward FAC is carried by antiparallel moving electrons of energies up to $2 \mathrm{keV}$, which is 




Fig. 15. Perpendicular electron fluxes from $\mathrm{C} 1$ (top panel), $\mathrm{C} 3, \mathrm{C} 2$ and $\mathrm{C} 4$ (bottom panel) presented as a function of geomagnetic latitude. The time interval covered by each of the satellites is 22:08-22:22 UT. The white dashed line shows the drift motion of the "original PCB" and the solid white lines the approximate locations of the final PCB. For details, see the text.

in good accordance with the mid-tail observations of Nagai et al. (2001) and Asano et al. (2006) of anti-parallel moving $3 \mathrm{keV}$ and $0.5-2 \mathrm{keV}$ electrons, respectively, towards to the reconnection site.

The absence of a similar downward FAC signature during the poleward expansion of the PCB beyond the satellites is easy to understand. If a boundary passes by the poleward moving satellites from the equatorward direction, the calculated FAC (assuming a stationary FAC sheet) would produce an apparent upward FAC sheet.

The cause of the suggested reconnection burst should obviously be driven by the IMF. Figure 2 shows a decrease in the IMF $B_{z}$ component to zero at about 22:08 UT under large $B_{y}$ positive conditions at the magnetopause. As discussed in the Introduction, reconnection may be expected even during northward IMF when the $B_{y}$ component is large. The observed temporal change in the IMF (with appropriate time delays) may produce a reconnection burst in the twisted magnetotail (Nishida et al., 1998; Grocott et al., 2005). After 22:10 UT the $B_{z}$ component of the IMF slowly increases whereas the $B_{y}$ component decreases and conditions may not be favourable to reconnection of closed field lines on the dayside and nightside anymore.

The final comment concerns comparison of Cluster PCB and PCB from EISCAT measurements. During the Cluster pass, the WEJ was decaying and the PCB determination from the EISCAT data was no longer straightforward. One can also note that the curves for the PCB by Methods 1 and 2 (see Sect. 2) in Fig. 5 are rather close to each other before 21:30 UT, whereas after that time larger deviations occur. The time resolution of the EISCAT PCB analysis was only 5 min during this time interval. One has to also remember that there is a longitudinal difference of about $8^{\circ}$ cgmLon between the EISCAT VHF beam and Cluster footpoints. The triangles with tip up show the final crossing of Cluster s/c to the polar cap and they are located between these two curves for the PCB, so a reasonable agreement is found.

\section{Conclusions}

We have studied the dynamics of the polar cap boundary and the poleward part of the nightside oval during 27 February 2004. The first part of this study is utilizing the method of determining the polar cap boundary (PCB) from the EISCAT measurements by Aikio et al. (2006) and the EISCAT measurements are put in the context of upward continued equivalent currents by MIRACLE magnetometer measurements. It was found that in the late expansion/early recovery phase, the PCB made a zig-zag-type motion with amplitude of $2.5^{\circ}$ cgmLat and a period of about $30 \mathrm{~min}$ near the magnetic midnight. We suggest that the poleward motions of the PCB were produced by bursts of enhanced reconnection at the near-Earth neutral line. The subsequent equatorward motions of the boundary may then be associated with the 
recovery of the merging line towards the equilibrium state (Cowley and Lockwood, 1992). The observed bursts of enhanced WEJ just equatorward of the polar cap boundary during poleward expansions are produced plausibly by particles accelerated in the vicinity of the neutral line and thus lend evidence to the Cowley-Lockwood paradigm.

The second part of the study presents coordinated groundbased and Cluster satellite measurements in the recovery phase of the same substorm. The Cluster satellites at a distance of $4.4 R_{E}$ showed outflow of $\mathrm{H}^{+}$and $\mathrm{O}^{+}$ions within the PSBL as noted in some earlier studies as well (e.g. Tung et al., 2001; Ober et al., 2001). We show that in this case the PSBL corresponded to a region of enhanced electron temperature in the ionospheric $\mathrm{F}$ region. It is suggested that the ion outflow originates from the $\mathrm{F}$ region as a result of increased ambipolar diffusion. At higher altitudes, the ions could be further energized by waves, which at Cluster altitudes were observed as BBELF fluctuations.

When approaching the PCB, Cluster particle data showed evidence of a sudden poleward expansion of the PSBL and the PCB by $2^{\circ}$ cgmLat during about 5 minutes. The shortlived reconnection burst in the recovery phase may be associated with a short-lived turning of the positive (northward) IMF $B_{z}$ to near zero during long-lasting positive $B_{y}$ conditions, which allows reconnection in an asymmetric tail to take place (e.g. Grocott et al., 2005).

The newly formed PSBL contained more intense electric field fluctuations and more intense ion outflow structures than the previously crossed PSBL, but the electron energies were smaller. The beginning of the poleward leap was associated with an intensification of the downward FAC at the boundary. We suggest that the observed downward FAC sheet at an altitude of $22000 \mathrm{~km}$ may be the high-altitude counterpart of the Earthward flowing FAC produced in the vicinity of the magnetotail neutral line by the Hall effect during a short-lived reconnection burst (Sonnerup, 1979). The PEACE data show that current carriers were electrons of a broad energy range from the lowest energies measured $(36 \mathrm{eV})$ to about $2 \mathrm{keV}$ and indicating ionospheric origin. The energy is of the same order as the measured energy of electrons streaming into the magnetic reconnection site in the magnetotail (Nagai et al., 1998; Asano et al., 2006). To our knowledge, there has not been conclusive evidence that this field-aligned current component would continue to the ionosphere. However, the data by Ober et al. (2001) and the data presented above, suggest this might be the case.

Acknowledgements. We thank R. Kuula for help in the analysis of EISCAT data. EISCAT is an international association supported by the research councils of Finland (SA), France (CNRS), Germany (MPG), Japan (NIPR), Norway (NFR), Sweden (VR) and the United Kingdom (PPARC). We acknowledge N. Ness at Bartol Research Institute and CDAWEB for the ACE data, WDC for Geomagnetism, Kyoto for the AL index, and C. Carlson at U.C.Berkeley and CDAWeb for the FAST data. We thank K. Kauristie at FMI for the MIRACLE all-sky camera data. The MIRA-
CLE network is operated within an international cooperation. The work by A. Kozlovsky has been supported by the Academy of Finland.

Topical Editor M. Pinnock thanks two anonymous referees for their help in evaluating this paper.

\section{References}

Aikio, A. T., Opgenoorth, H. J., Persson, M. A. L., and Kaila, K. U.: Ground-based measurements of an arc-associated electric field, J. Atmos. Terr. Phys., 55, 797-808, 1993.

Aikio, A. T., Mursula, K., Buchert, S., Forme, F., Amm, O., Marklund, G., Dunlop, M., Andre, M., Fontaine, D., Vaivads, A., and Fazakerley, A.: Temporal evolution of two auroral arcs as measured by the Cluster satellite and coordinated ground-based instruments, Ann. Geophys., 22, 4089-4101, 2004,

http://www.ann-geophys.net/22/4089/2004/.

Aikio, A. T., Pitkänen, T., Kozlovsky, A., and Amm, O.: Polar cap boundary in the nightside ionosphere during substorm growth and expansion, Ann. Geophys., 24, 1905-1917, 2006, http://www.ann-geophys.net/24/1905/2006/.

André, M., Norqvist, P., Andersson, L., Eliasson, L., Eriksson, A. I., Blomberg, L., Erlandson, R. E., and Waldemark, J.: Ion energization mechanisms at $1700 \mathrm{~km}$ in the auroral region, J. Geophys. Res., 103, 4199-4222, 1998.

Asano, Y., Nakamura, R., Runov, A., et al.: Detailed analysis of low-energy electron streaming in the near-Earth neutral line region during a substorm, Adv. Space Res., 37, 1382-1387, 2006.

Baker, J. B., Clauer, C. R., Ridley, A. J., Papitashvili, V. O., Brittnacher, M. J., and Newell, P. T.: The nightside poleward boundary of the auroral oval as seen by DMSP and the ultraviolet imager, J. Geophys. Res., 105, 21 267-21 280, 2000.

Balogh, A., Dunlop, M. W., Cowley, S. W. H., et al.: The Cluster magnetic field investigation, Space Sci. Rev., 79, 65-91, 1997.

de la Beaujardiere, O., Lyons, L. R., and Friis-Christensen, E.: Sondrestrom radar measurements of the reconnection electric field, J. Geophys. Res., 96, 13 907-13 912, 1991.

Blanchard, G. T., Lyons, L. R., Samson, J. C., and Rich, F. J.: Locating the polar cap boundary from observations of $6300 \AA$ auroral emission, J. Geophys. Res., 100, 7855-7862, 1995.

Blanchard, G. T., Lyons, L. R., de la Beaujardiere, O., Doe, R. A., and Mendillo, M.: Measurement of the magnetotail reconnection rate, J. Geophys. Res., 101, 15 265-15 276, 1996.

Brittnacher, M., Fillingim, M., Parks, G., Germany, G., and Spann, J.: Polar cap area and boundary motion during substorms, J. Geophys. Res., 104, 12 251-12 262, 1999.

Chisham, G., Freeman, M. P., and Sotirelis, T.: A statistical comparison of SuperDARN spectral width boundaries and DMSP particle precipitation boundaries in the nightside ionosphere, Geophys. Res. Lett., 31, L02804, doi:10.1029/2003GL019074, 2004.

Cowley, S. W. H. and Lockwood, M.: Excitation and decay of solar-wind driven flows in the magnetosphere-ionosphere system, Ann. Geophys., 10, 103-115, 1992,

http://www.ann-geophys.net/10/103/1992/.

Davies, J. A., Yeoman, T. K., Rae, I. R., Milan, S. E., Lester, M., Lockwood, M., and McWilliams, A.: Ground-based observations of the auroral zone and polar cap ionospheric responses to dayside transient reconnection, Ann. Geophys., 20, 781-794, 
2002 ,

http://www.ann-geophys.net/20/781/2002/.

Eastman, T. E., Frank, L. A., Peterson, W. K., and Lennartson, W.: The plasma sheet boundary layer, J. Geophys. Res., 89, 15531572, 1984.

Greenwald, R. A., Baker, K. B., Dudeney, J. R., Pinnock, M., Jones, T. B., et al.: DARN/SUPERDARN A Global View of the Dynamics of High-Latitude Convection, Space Sci. Rev. 71, 761-796, 1995.

Grocott, A., Yeoman, T. K., Milan, S. E., and Cowley, S. W. H.: Interhemispheric observations of the ionospheric signature of tail reconnection during IMF-northward non-substorm intervals, Ann. Geophys., 23, 1763-1770, 2005, http://www.ann-geophys.net/23/1763/2005/.

Gustafsson, G., Boström R., Holback, B., et al.: The electric field and wave experiment for the Cluster mission, Space Sci. Rev., 79, 137-156, 1997.

Hubert, B., Milan, S. E., Grocott, A., Blockx, C., Cowley, S. W. H., and Gérard, J.-C.: Dayside and nightside reconnection rates inferred from IMAGE FUV and Super Dual Auroral Radar Network, J. Geophys. Res., 111, A03217, doi:10.1029/2005JA011140, 2006.

Johnstone, A. D., Alsop, C., Burge, S., et al.: PEACE: a plasma electron and current experiment, Space Sci. Rev., 79, 351-398, 1997.

Keiling, A., Wygant, J., Cattel, C., Johnson, M., Temerin, M., Mozer, F., Kletzing, C., Scudder, J., Russell, C., and Peterson, W.: Properties of large electric fields in the plasma sheet at 4$7 R_{E}$ measured with Polar, J. Geophys. Res., 106, 5779-5798, 2001.

Kepko, L., Spence, H. E., and Singer, H. J.: ULF waves in the solar wind as direct drivers of magnetospheric pulsations, Geophys. Res. Lett., 29, 1197, doi:10.1029/2001GL014405, 2002.

Kepko, L. and Spence, H. E.: Observations of discrete, global magnetospheric oscillations directly driven by solar wind density variations, J. Geophys. Res., 108, 1257, doi:10.1029/2002JA009676, 2003.

Lockwood, M. and Fuller-Rowell, T. J.: The modelled occurrence of non-thermal plasma in the ionospheric F-region and the possible consequences for ion outflows into the magnetosphere, Geophys. Res. Lett., 14, 371-374, 1987a.

Lockwood, M. and Fuller-Rowell, T. J.: Correction to "The modelled occurrence of non-thermal plasma in the ionospheric $\mathrm{F}$ region and the possible consequences for ion outflows into the magnetosphere", Geophys. Res. Lett., 14, 581-581, $1987 \mathrm{~b}$.

Lockwood, M. and Cowley, S. W. H.: Comment on "A statistical study of the ionospheric convection response to changing interplanetary magnetic field conditions busing the assimilative mapping of ionospheric electrodynamics technique" by A. J. Ridley et al., J. Geophys. Res., 104, 4387-4391, 1999.

Lockwood, M., Cowley, S. W. H., and Freeman, M. P.: The excitation of plasma convection in the high-latitude ionosphere, J. Geophys. Res., 95, 7961-7972, 1990.

Lockwood, M., Moen, J., van Eyken, A. P., Davies, J. A., Oksavik, K., and McCrea, I. W.: Motion of the dayside polar cap boundary during substorm cycles: I. Observations of pulses in the magnetopause reconnection rate, Ann. Geophys., 23, 3495-3511, 2005, http://www.ann-geophys.net/23/3495/2005/.

Lynch, K. A., Bonnel, J. W., Carlson, C. W., and Preria, W.
$\mathrm{J} .:$ Return current region aurora: $\mathrm{E}_{\|}, \mathrm{j}_{z}$, particle energization, and broadband ELF wave activity, J. Geophys. Res., 107, doi:10.1029/2001JA900134, 2002.

McPherron, R. L.: Magnetospheric dynamics, in: Introduction to Space Physics, edited by: Kivelson, M. and Russel, C. T., Cambridge University Press, 400-458, 1995.

Milan, S. E., Lester, M., Cowley, S. W. H., Oksavik, K., Brittnacher, M., Greenwald, R. A., Sofko, G., and Villain, J.-P.: Variations in the polar cap area during two substorm cycles, Ann. Geophys., 21, 1121-1140, 2003, http://www.ann-geophys.net/21/1121/2003/.

Moen, J., Lockwood, M., Oksavik, K., Carlson, H. C., Denig, W. F., van Eyken, A. P., and McCrea, I. W.: The dynamics and relationships of precipitation, temperature and convection boundaries in the dayside auroral ionosphere, Ann. Geophys., 22, 1973-1987, 2004, http://www.ann-geophys.net/22/1973/2004/.

Nagai, T., Shinohara, I., Fujimoto, M., Hoshino, M., Saito, Y., Machida, S., and Mukai, T.: Geotail observations of the Hall current system: Evidence of magnetic reconnection in the magnetotail, J. Geophys. Res., 106, 25 929-25 949, 2001.

Nagai, T., Shinohara, I., Fujimoto, M., Machida, S., Nakamura, R., Saito, Y., and Mukai, T.: Structure of the Hall current system in the vicinity of the magnetic reconnection site, J. Geophys. Res., 108, 1357, doi:10.1029/2003JA009900, 2003.

Nakamura, R., Amm, O., Laakso, H., Draper, N. C., Lester, M., Grocott, A., Klecker, B., McCrea, I. W., Balogh, A., Réme, H., and Andé, M.: Localized fast flow disturbance observed in the plasma sheet and in the ionosphere, Ann. Geophys., 23, 553566, 2005,

http://www.ann-geophys.net/23/553/2005/.

Newell, P. T., Feldstein, Y. I., Galperin, Y. I., and Meng, C.-I.: Morphology of nightside precipitation, J. Geophys. Res., 101, 10737-10748, 1996a.

Newell, P. T., Feldstein, Y. I., Galperin, Y. I., and Meng, C.-I.: Correction to "Morphology of nightside precipitation" by P. T. Newell, Y. I. Feldstein, Y. I. Galperin, and C.-I. Meng, J. Geophys. Res., 101, 17419-17 421, 1996b.

Nishida, A., Mukai T., Yamamoto, T., Kokubun, S., and Maezawa, K.: A unified model of magnetotail convection in geomagnetically quiet and active times, J. Geophys. Res., 103, 4409-4418, 1998.

Ober, D. N., Maynard, N. C., Burke, W. J., Peterson, W. K., Sigwarth, J. B., Frank, L. A., Scudder, J. D., Hughes, W. J., and Russell, C. T.: Electrodynamics of the poleward auroral border observed by Polar during a substorm on April 22, 1998, J. Geophys. Res., 106, 5927-5943, 2001.

Ostgaard, N., Moen, J., Mende, S. B., Frey, H. U., Immel, T. J., Gallop, P., Oksavik, K., and Fujimoto, M.: Estimates of magnetotail reconnection rate based on IMAGE FUV and EISCAT measurements, Ann. Geophys., 23, 123-134, 2005, http://www.ann-geophys.net/23/123/2005/.

Reiff, P. H. and Burch, J. L.: IMF By-dependent dayside plasma flow and Birkeland current in the dayside magnetosphere, 2, A global model for northward and southward IMF, J. Geophys. Res., 90, 1595-1609, 1985.

Réme, H., Aoustin, C., Bosqued, J. M., Dandouras, I., Lavraud, B., et al.: First multispacecraft ion measurements in and near the Earth's magnetosphere with the identical Cluster ion spectrome- 
try (CIS) experiment, Ann. Geophys., 19, 1303-1354, 2001, http://www.ann-geophys.net/19/1303/2001/.

Russell, C. T.: The configuration of the magnetosphere, in: Critical Problems of Magnetospheric Physics, edited by: Dyer, E. R., pp. 1-16, National Academy of Sciences, Washington D.C., 1972.

Siscoe, G. L. and Huang, T. S.: Polar cap inflation and deflation, J. Geophys. Res., 90, 543-547, 1985.

Sonnerup, B. U. O.: Magnetic field reconnection, in: Solar System Plasma Physics, vol. 3, edited by: Lanzerotti, L. T., Kennel, C. F., and Parker, E. N., pp. 45-108, North-Holland, New York, 1979.

Sotirelis, T., Newell, P., and Meng, C.-I.: Low Altitude Signatures of Magnetotail Reconnection, J. Geophs. Res., 104, 17311$17321,1999$.

Tanaka, T.: Configuration of the magnetosphere-ionosphere convection system under northward IMF conditions with nonzero IMF By, J. Geophys. Res., 104, 14 683-14 690, 1999.

Tung, Y.-K., Carlson, C. W., McFadden, J. P., Klumpar, D. M., Parks, G. K., Peria, W. J., and Liou, K.: Auroral polar cap boundary ion conic outflow observed on FAST, J. Geophys. Res., 106, 3603-3614, 2001.

Ueno, G., Ohtani, S., Saito, Y., and Mukai, T.: Fieldaligned currents in the outermost plasma sheet boundary layer with Geotail observation, J. Geophys. Res., 107, 1399, doi:10.1029/2002JA009367, 2002.

Ueno, G., Ohtani, S., Mukai, T., Saito, Y., and Hayakawa, H.: Hall current system around the magnetic neutral line in the magnetotail: Statistical study, J. Geophys. Res., 108, 1347, doi:10.1029/2002JA009733, 2003.
Vanhamäki, H., Amm, O., and Viljanen, A.: 1-dimensional upward continuation of the ground magnetic field disturbance using spherical elementary current systems, Earth Planets Space, 55, 613-625, 2003.

Wild, J. A., Milan, S. E., Owen, C. J., Bosqued, J. M., Lester, M., Wright, D. M., Frey, H., Carlson, C. W., Fazakerley, A. N., and Réme, H.: The location of the open-closed magnetic field line boundary in the dawn sector auroral ionosphere, Ann. Geophys., 22, 3625-3639, 2004, http://www.ann-geophys.net/22/3625/2004/.

Wilson, G. R., Ober, D. M., Germany, G. A., and Lund, E. J.: The relationship between suprathermal heavy ion outflow and auroral electron energy deposition: Polar/Ultra-violet Imager and Fast Auroral Snapshot/ Time-of-Flight Energy Angle Mass Spectrometer observations, J. Geophys. Res., 106, 18 981-18 993, 2001.

Wilson, G. R., Ober, D. M., Germany, G. A., and Lund, E. J.: Nightside auroral zone and polar cap ion outflow as a function of substorm size and phase, J. Geophys. Res., 109, A02206, doi:10.1029/2003JA009835, 2004.

Yamade, Y., Fujimoto, M., Yokokawa, N., and Nakamura, M. S.: Field-aligned currents generated in magnetotail reconnection: 3D Hall-MHD simulations, Geophys. Res. Lett., 27, 1091-1094, 2000.

Yau, A. and André, M.: Source of ion outflow in the high latitude ionosphere, Space Sci. Rev., 80, 1-26, 1997. 